\title{
Indian Ocean variability in the CMIP5 multi-model ensemble: The basin mode
}

\author{
Yan DU* \\ State Key Laboratory of Tropical Oceanography, South China Sea Institute of Oceanology, Chinese \\ Academy of Sciences, Guangzhou, China \\ Shang-Ping XIE \\ International Pacific Research Center and Department of Meteorology, University of Hawaii at \\ Manoa, Honolulu, Hawaii; Physical Oceanography Laboratory, Ocean University of China, \\ Qingdao, China; Scripps Institution of Oceanography, UC San Diego, La Jolla, California

\section{Ya-Li YANG}

State Key Laboratory of Tropical Oceanography, South China Sea Institute of Oceanology, Chinese Academy of Sciences, Guangzhou, China

Xiao-Tong ZHENG

Physical Oceanography Laboratory and Key Laboratory of Ocean-Atmosphere Interaction and Climate in Universities of Shandong, Ocean University of China, Qingdao, China

Lin LIU

First Institute of Oceanography, State Oceanic Administration, China

Gang HUANG

Key Laboratory of Regional Climate-Environment Research for Temperate East Asia, Institute of Atmospheric Physics, Chinese Academy of Sciences, Beijing, China

(Submitted to Journal of Climate, September 16, 2012; Revised January 31, 2013, and March 12, 2013; accepted March 15, 2013)

* Corresponding author: Yan DU, State Key Laboratory of Tropical Oceanography, South China Sea Institute of Oceanology, 164 West Xingang Road, Guangzhou 510301, China. E-mail:

duyan@scsio.ac.cn 


\begin{abstract}
:
This study evaluates the simulation of the Indian Ocean Basin (IOB) mode and relevant physical processes in Coupled Model Intercomparison Projects phase 5 (CMIP5) models. Historical runs from 20 CMIP5 models are available for the analysis. They reproduce the IOB mode and its close relationship to El Niño/Southern Oscillation (ENSO). Half of the models capture key IOB processes: a downwelling oceanic Rossby wave in the southern tropical Indian Ocean (TIO) precedes the IOB development in boreal fall, and triggers an anti-symmetric wind anomaly pattern across the equator in the following spring. The anomalous wind pattern induces a second warming in the north Indian Ocean (NIO) through summer and sustains anti-cyclonic wind anomalies in the Northwest Pacific by radiating a warm tropospheric Kelvin wave. The second warming in the NIO is indicative of ocean-atmosphere interaction in the interior TIO. More than half of models display a double peak in NIO warming as observed following El Niño while the rest show only one winter peak. The inter-model diversity in the characteristics of the IOB mode seems related to the thermocline adjustment in the south TIO to ENSO-induced wind variations. Almost all the models show multi-decadal variations in IOB variance, possibly modulated by ENSO.
\end{abstract}

\title{
1. Introduction
}

Interannual basin-wide sea surface temperature (SST) warming over the tropical Indian Ocean (TIO) is highly correlated with El Niño/Southern Oscillation (ENSO) (Klein et al. 1999; Saji et al. 2006). Recent diagnostic studies reveal that this Indian Ocean basin (IOB) mode is not a passive response to ENSO but involves air-sea interaction in the TIO and exerts important climatic influences on climate over the Northwest Pacific (NWP; Yang et al. 2007; Xie et al. 2009, 2010; Du et al. 2009, 2011; Huang et al. 2010) and Australia (e.g. Taschetto et al. 2011).

In the empirical orthogonal function (EOF) analysis, the basin-wide warming/cooling is the first mode and reaches a maximum during March-May about one season after the mature phase of ENSO. Early studies revealed surface heat fluxes, specifically the wind-induced latent heat flux and cloud-induced shortwave radiation flux anomalies, are important for this warming (Klein et al. 1999; Alexander et al. 2002; Ohba and Ueda 2005). In response to El Niño, the atmospheric circulation and convection weaken over the TIO, resulting in the increase of solar radiation and decrease of 
latent heat flux loss. Both contribute to the SST warming.

Recent studies found that the SST warming in the Indian Ocean has regional features with distinct evolutions and mechanisms. In the southwest TIO (SWIO), both heat budget analysis and model investigations indicated that surface fluxes could not explain the warming and suggested the importance of ocean dynamics (Klein et al. 1999; Lau and Nath 2003). There, the positive curls between the weak equatorial westerlies and the easterly trades to the south maintain upwelling and thus a thermocline dome in the climatology (Hermes and Reason 2008; Yokoi et al 2008), conducive to subsurface influence on SST variability. During an El Niño event, an anti-cyclonic atmospheric circulation over the southeast TIO (SEIO) forces a downwelling Rossby wave. This downwelling Rossby wave propagates westward and suppresses the upwelling in the thermocline dome (e.g. Masumoto and Meyers 1998; Yu et al. 2005). Through this mechanism, the SWIO SST warms up and persists to the summer even as El Niño decays (Xie et al. 2002).

The SWIO warming increases atmospheric convection in the boreal spring following the El Niño (Xie et al. 2002; Annamalai et al. 2005). The intensified convection anchors an anti-symmetric atmospheric circulation pattern across the equator, with northeasterly/northwesterly wind anomaly north/south of the equator. The atmospheric asymmetry is due to the SST gradient between the north and south and the reverse of the Coriolis force across the equator in the form of Wind-Evaporation-SST (WES) feedback (Kawamura et al. 2001; Wu et al. 2008). In the north Indian Ocean (NIO), the northeasterly wind anomaly enhances the winter monsoon in the early-spring season and cools down the SST through the loss of latent heat flux. When the monsoon changes to southwesterly in May, the northeasterly anomaly sustained by the SWIO warming weakens the monsoonal wind. The reduced latent heat flux causes a second SST warming north of the equator, from the NIO to the South China Sea (Du et al. 2009). The ocean dynamics, through reducing the Ekman transport and upwelling by weakened monsoonal wind, re-enforces the SST warming in the coastal region, off the Somali coast in the Arabian Sea (Izumo et al, 2008) and the Vietnam coast in the South China Sea (Xie et al., 2003).

These processes illustrate the importance of air-sea interaction and ocean dynamics in the Indian Ocean, not simply a passive response to ENSO via the "atmospheric bridge" (Alexander et al 2002). The complexity of the above processes poses a challenge for the coupled ocean-atmosphere general circulation models (CGCMs) to simulate Indian Ocean climate and SST 
variability. In an analysis of the World Climate Research Programme's (WCRP's) Coupled Model Intercomparison Projects phase 3 (CMIP3), Saji et al. (2006) found that most of the models, 15 out of 17, capture the IO basin wide warming associated with ENSO with a few months delay. The models without the IOB mode usually have weak or wrong ENSO simulations. Although the thermocline dome in the southwestern IO was simulated in most models (Yokoi et al 2009), the ocean Rossby wave propagation response to ENSO was present only in a subset of models. For example, the GFDL model confirms that the slow propagating Rossby wave in the south TIO is the key to persisting the IOB warming into the following summer after ENSO, indicating the role of ocean dynamics in IO SST variability (Zheng et al. 2011).

The present study evaluates the simulation of the IOB mode and its relationship to ENSO in the large CMIP5 multi-model ensemble. It extends Saji et al.'s (2006) CMIP3 analysis not only in using the new CMIP5 ensemble (Taylor et al. 2012) but more importantly, in taking advantage of emerging results from recent studies that the IOB mode is not uniform over the TIO basin but displays characteristic sub-basin variations indicative of ocean-atmosphere interactions within the basin. Specifically, we examine the wind forcing of the downwelling ocean Rossby wave in $\operatorname{DJF}(0 / 1)$ at the peak of El Niño, the development of the anti-symmetric atmospheric pattern in MAM(1), and the second peak of the NIO warming in JJA(1). We show that most CMIP5 models succeed in capturing salient features and key physical processes of the IOB mode. Our results form the basis for further in-depth studies of ENSO teleconnection and internal ocean-atmosphere feedback over the TIO basin. This is important as recent studies show that the IOB mode provides predictability for summer climate anomalies over the NWP and East Asia (Chowdary et al. 2010, 2011).

The rest of the paper is organized as follows. Section 2 describes the CMIP5 dataset. Section 3 assesses the IOB simulation in CMIP5 models. Section 4 explores interdecadal and long term change of the IOB mode. Section 5 is a summary.

\section{Data}

The WCRP CMIP5 multi-model products used in this study are obtained from the Earth System Science Portals in different institutes and countries. To compare with observations, the analysis 
focuses on the climate of the historical runs, which are forced with the observed history of GHG concentrations, solar radiation, and other climate forcing. At the present stage, we have obtained necessary data from 20 models. Table 1 lists the names, institutions, and resolutions of the models. Monthly mean output is used, including SST, SSH, $10 \mathrm{~m}$ wind, precipitation, and sea level pressure (SLP). The historical runs span from 1870 to 2005 . This study mainly focuses on the last 30 years period from 1976 to 2005, but analyzes the multi-decadal variation based on the 136-year simulation.

For observations, we use the extended reconstructed SST (ERSST; Smith et al 2008) and Hadley Centre Sea Surface Temperature dataset (HadISST and HadSST3, Rayner et al. 2003, Kennedy et al. 2011); surface winds from the monthly mean reanalysis from the National Centers for Environmental Prediction-Department of Energy (NCEP-DOE) (Kanamitsu et al. 2002), available for 1979-2008; Hadley Centre Sea Level Pressure (Allan and Ansell 2006) from 1979 to 2008; the monthly Climate Prediction Center (CPC) Merged Analysis of Precipitation (CMAP) (Xie and Arkin 1997) from 1979 to 2008; sea surface height (SSH) from the Simple Ocean Data Assimilation reanalysis (SODA; version 2.6, from 1979 to 2008; Carton and Giese 2008), and from the multi-satellite altimetry observations for the period from 1993 to 2011, merged and distributed by the Collecte Localisation Satellites (CLS) Space Oceanographic Division of Toulouse in France. The mean climatological annual cycle is defined using data for the last 30-year period in models and reanalyses or the available period for satellite altimetry. Anomalies are calculated by subtracting the monthly mean values from their respective climatology. A 4-84 months Hanning band-passing filter is applied to extract interannual anomalies, and two years periods is removed from both edges before further analysis.

We perform regression and correlation analyses referenced to the Niño-3.4 $\left(5^{\circ} \mathrm{S}-5^{\circ} \mathrm{N}\right.$, $\left.170^{\circ} \mathrm{W}-120^{\circ} \mathrm{W}\right) \mathrm{SST}$ index averaged from November(0) to January(1) [NDJ(0/1)]. Here, numerals " 0 " and " 1 " denote the developing and decay years of El Niño, respectively. The IOB mode index is defined as SST averaged in $\left(20^{\circ} \mathrm{S}-20^{\circ} \mathrm{N}, 40^{\circ} \mathrm{E}-110^{\circ} \mathrm{E}\right)$. Note that in some figures, anomalies are the regression coefficients in field unit per ${ }^{\circ} \mathrm{C}$ of Nino3.4 NDJ SST or NIO SST AMJ SST anomaly but only the field unit is given in figure captions. A $t$ test is conducted on the analyses, only the results with the statistical significance at the $90 \%$ confidence level are shown in spatial plots. To be statistically accurate for a small sample, the standard deviation across models is calculated on the 
Fisher transformation to stabilizes the variance (Fisher 1921), and then transformed back to correlation to represent graphically the interval of confidence, which become "asymmetric" (e.g. in Figures 10 and 14b-c). The interdecadal analyses in the discussion section is based on the variance calculation and correlation in 21-year running windows.

\section{IOB mode in CMIP5 models}

\section{a. EOF modes}

The basin wide warming pattern emerges as the first EOF mode of IO SST variability, covering the entire TIO basin as well as the South China Sea and Indonesian Seas (Figure 1). 80\% of models, 16 out of 20 , produce a spatial pattern similar to observations, and the rest, 4 out of 20 , present an IOD like pattern. The pattern correlation coefficients between observation and simulations have been calculated, most of them higher than 0.9 (Figure 1). The explained variance contributions in those 16 models range from $22 \%$ to $49 \%$, compared to $40 \%$ in ERSST ( $42 \%$ in HadISST, figure not shown). The second EOF mode explains variance ranging from $9 \%$ to $20 \%$, compared to $13 \%$ in ERSST (15\% in HadISST; not shown). These results are consistent with previous studies (Weare 1979; Klein et al. 1999; Saji et al. 1999, 2006; Du et al. 2009; Zheng et al. 2010, 2011). Note that the IOB mode is the second EOF mode for CSIRO-Mk3.6, and the IOD is the first EOF mode (Figure 1). INMCM4's first EOF mode shows an IOD pattern and the second mode (explaining $14 \%$ variance) is also IOD like (IOB pattern correlation coefficient only 0.65 ). The first EOF mode in three models (ACCESS1.0, HadGEM2-ES, and MPI-ESM-LR) is IOD like, with a negative sign off the Java coast. In Figure 1, the composite of all models is marked as MME (multi-model ensemble) composite. Note if the four IOD-like models are removed from the composite, the explained variance in MME increase from 32\% to $34 \%$ and pattern correlation coefficients from 0.91 to 0.94 . Those changes are not significant. We use all member ensemble mean in the following composite. The variance of PC1 (PC2 in CSIRO-Mk3.6 and INMCM4), corresponding to the IOB pattern, increases in January-July season, consistent with observations (Figure 2). There is some model diversity in the amplitude phase locking.

In the spatial pattern of the first EOF mode, most models reproduce the maximum SST variance in the central TIO. A few models (e.g. ACCESS1.0, MPI-ESM-LR, MRI-CGCM3, and 
INMCM4) show a maximum along the west coast of the Arabian Sea and west equatorial region, suggesting the influence of strong upwelling off the Somali Coast and thermocline variation due to the downwelling equatorial Rossby wave, respectively. The maximum SST in the SWIO reaches far west in models than that in observations, implying the impact of the downwelling equatorial Rossby wave on the thermocline and SST in model. These models share a common cold tongue like structure along the east equatorial region, suggesting an overestimation of upwelling processes off Sumatra. There, a thick barrier layer usually impedes the deep thermocline water from being entrained into the mixed layer (e.g. Qu and Meyers 2005; Masson et al. 2005), not in favor of SST variations (Du et al. 2005) except during strong IOD events (Du et al. 2008). The second EOF mode shows that these models overestimate the SST cooling off Sumatra (not shown). An ongoing study reveals the mean depth of the thermocline off Sumatra in these models is too shallow compared to observations, inducing a strong cold tongue structure (Zheng et al. 2013).

\section{b. ENSO simulation and correlation with $I O B$}

ENSO in the tropical Pacific is a major forcing for TIO SST variability. The simulated ENSO varies in amplitude, frequency, and pattern from model to model. Figure 3 shows the standard deviation of SST anomalies (SSTa) along the equator from the Indian to Pacific Ocean. In observations, large SST variations are located in the central and eastern Pacific, with a shift tendency of a westward propagation. The comparison with the seasonal climatological cycle indicate that the largest cooling in the CMIP5 MME locates too far away from the east Pacific coast, implying a possible discrepancy in simulating the Peru coastal upwelling. The amplitude of interannual SST variation is over $1^{\circ} \mathrm{C}$ in the boreal winter season in the Pacific, while in the Indian Ocean it is weaker and peaks in boreal summer season. About half of models show a clear resemblance in the ENSO evolution to observations while the rest still exhibit large discrepancy (not shown). For example, the eastward propagation signature of the SST variations is mixed with a westward propagation; the maximum of SST variation shifts too far west; and the seasonality does not show a robust phase locking as in observations. Similar issues were also noted in an earlier version of CMIP3 (e.g. Guilyardi, 2006). Despite the above discrepancies, the ENSO characteristics in the multi-model ensemble are generally consistent with observations (Figure 3). Note the asymmetry of ENSO and IOB and their relationship are also important, not discussed in detail in this study, and worth a further investigation in the future (e.g. An and Jin 2004; Kug et al. 2005; 
Ohba and Ueda 2009; Okumura et al. 2011).

The IOB mode is forced by ENSO. A scatter diagram of root mean square (RMS) variance (Figure 4a), indicates that the IOB amplitude is related to that of ENSO. Half of the models simulate ENSO amplitudes comparable to observations. A Taylor diagram compares the IOB-ENSO relationship between models and observations (Figure 4b). The correlation coefficients between IOB and ENSO in CMIP5 models range from 0.43 to 0.91 , compared to 0.84 in ERSST and 0.86 in HadSST3. To avoid the influence of ENSO amplitude, the standard deviation of IOB is normalized by dividing the standard deviation of the Niño 3.4 SST index in each model (Figure 4a). The IOB amplitude is about a quarter of that of ENSO in more than half of the models, consistent with observations. Figure $4 \mathrm{~b}$ suggests the IOB-ENSO amplitude correlation is not related to their amplitude ratio. MIROC-ESM has the largest amplitude ratio, but its correlation with ENSO is among the smallest.

In observations, Niño-3.4 SSTa develop in April-June(0), and decays rapidly in April-June(1) over one year period (Figures 5a\&5b). The ENSO development in CMIP5 models generally agrees with observations with 1-3 months lead/lag in a given model (Figures $5 \mathrm{c} \& 5 \mathrm{e}$ ). At the decay stage, the models show much diversity. A few models transit from a positive to negative event (e.g. MRI-CGCM3 and CNRM-CM5), suggesting a dominant two-year period (Figure 5d). By contrast, in GFDL-ESM2M and MIROC5, the SSTa can persist longer into the JAS(1) season, possibly due to a long lived ENSO in those models. The low auto-correlation in INMCM4 suggests a high noise level in ENSO simulation. This model seems to simulate a weak air-sea interaction, and weak IO variability.

TIO SST warming delays behind ENSO by 4-6 months to reach the maximum (Figures 5a-c), and lingers into August-September(1) (Xie et al. 2009; Chowdary et al. 2012; Wu et al. 2012). Recent studies view the TIO as a capacitor (Yang et al. 2007; Xie et al. 2009). The TIO stores the heat during the development and releases the heat during the decay of ENSO. In many models, the TIO warming persists 2-3 months longer than observations into October-November(1) (Figure 5d), possibly due to long lived ENSO in these models. For the long persistence of TIO warming, the second NIO warming plays an important role. 13 out of 20 models show a double peak structure in NIO warming (Figure 5f). In 13 models, the NIO SST-ENSO correlations barely pass the 90\% significant level for the February-March minimum between the two peaks, while both peaks pass 
the 95\% significant level. Based on the Fisher (1921) transformation, we test the statistical significance for the difference between each peak and the February-March minimum. In 8 (6) out of 13 models, the difference between the second (first) peak and minimum passes the 95\% (90\%) significant confidence level, consistent with observations. Thus the double peak structure is significant in about a half of the models. Previous studies found that the second peak of NIO warming involves internal air-sea interaction within the TIO, and is the key for the TIO warming to persist into the following summer (Du et al. 2009).

\section{c. Atmospheric forcing over the southeast TIO}

During the development phase of El Niño, an anomalous high-pressure system develops over the Marinetime Continent as part of the Southern Oscillation (Wallace et al. 1998; Wang et al. 2003). The change of atmospheric convection induces anti-cyclonic wind anomalies over the SEIO (Figure 6). During $\mathrm{SON}(0)$ season, the northeast flank of the anti-cyclonic atmospheric circulation favors surface evaporation, vertical mixing, coastal upwelling, and thus SST cooling off Sumatra and Java (Shinoda et al. 2004). The southwest flank weakens the trade wind in the central south Indian Ocean and warming the SST (Yu and Rienecker, 1999). Along with the slowdown of the Walker Circulation, the suppressed convection over and west of Sumatra and Java decrease precipitation over the region (Yamagata et al. 2004).

Most models simulate the anti-cyclonic circulation over the SEIO. The results have been normalized by the ratio of the standard deviation of Niño 3.4 SST in observations to models. Similar normalization has been made for other variables in the following figures. Particularly, the simulated anti-cyclonic circulation occupies the entire south TIO in the MME composite. Associated SST cooling and abnormal precipitation extend into the central equatorial Indian Ocean. The deviations of the simulation from observations may lie in the departure of ENSO simulation in the Pacific. In many models ENSO (Figures $3 \& 6$ ) extends to $130^{\circ} \mathrm{E}-150^{\circ} \mathrm{E}$, about $20^{\circ}-40^{\circ}$ longitude too westward compared to observations. Note that the anti-cyclonic atmospheric circulation in some models is not phase-locked in SON season. Take GISS-E2-H as an example, the appearance of the anti-cyclonic atmospheric circulation delays by 1-2 months, a consequence of the diversity of model ENSO (Figure 5d-f).

At the mature phase of El Niño (Figure 7), in the SEIO, the prevailing wind shift to northeasterly, a change important for the development of interannual anomalies (Nicholls 1984; 
Klein et al. 1999; Shinoda et al. 2004; Ohba and Ueda 2009). The northeast flank of the anti-cyclonic atmospheric circulation, particular in the region west of Sumatra and Java, weakens, and so do the coastal upwelling and surface evaporation (Murtugudde et al. 2000). Together with the increased solar radiation due to suppressed convective clouds, the SST in the SEIO switches from negative towards positive in the following season (Tokinaga and Tanimoto 2004). In the southwest flank of the anti-cyclonic atmospheric circulation, the reduced trade winds enhance the SST warming by decreasing latent heat flux release. The precipitation increase extends southeastward from the west TIO to the central south Indian Ocean.

Most models capture the anti-cyclonic atmospheric circulation in $\operatorname{DJF}(0 / 1)$, with similar SST and precipitation patterns to observations. Particularly, the east-west contrast of rainfall pattern reflects the Walker Circulation reduction during the mature phase of El Niño (Wang and Picaut 2004). A few models (e.g. GFDL-ESM2G, HadGEM2-ES, MRI-CGCM3, and MPI-ESM-LR; figure not shown) overestimate the atmospheric circulation in the NIO or easterly wind along the equator. The signature seems an extension of the anti-cyclonic atmospheric circulation over the NWP, as part of atmospheric Rossby waves induced by local negative SSTa at the ENSO mature phase (Wang et al. 2000; Wang and Picaut 2004). This circulation causes SST warming withdraw to the west [Figure 7; also refer to (Xie et al. 2009) and (Huang et al., 2010)]. The westward extension of the anti-cyclonic atmospheric circulation over the NWP seems related to the ENSO structure that is displaced westward compared to observations in the equatorial region ( $\mathrm{Hu}$ et al. 2013).

\section{d. Oceanic Rossby wave in the south TIO}

In $\mathrm{SON}(0)-\mathrm{NDJ}(0 / 1)$ season, the anti-cyclonic atmospheric circulation over the SEIO forces and strengthens downwelling Rossby waves that propagate westward. The SST warming co-propagates with the oceanic Rossby wave (Xie et al. 2002; Du et al. 2009). SSH anomaly (SSHa) reaches the maximum in April(1) (Figure 8), whereas SST anomaly peaks in May-June(1) (Figure 9a). The 1-2 month delay in the SST response is due to the annual shoaling of the thermocline in June-July (Figure 9b; Perigaud and Delecluse 1993; Masumoto and Meyers 1998), which enhances thermocline feedback. The interannual depression of the shallow thermocline reduces the cold upwelling water into the mixed layer and increases the SST, which explains why the surface heat flux is not important for the SST warming during the May-June(1) (Klein et al. 1999; Yokoi et al. 2012). The Rossby wave induced warming over SWIO affects the atmosphere in this period (Xie et 
al. 2002; Annamalai et al. 2005; Schott et al. 2009). Precipitation increases during February-June(1), with the maximum in April(1) (Figure 9c), which prolongs the annual precipitation in this season (Figure 9d).

In Figure 8, half of models reproduce the Rossby wave propagation, with some differences in position and phase. Convection anomaly seems related to the Rossby wave in these models. Abnormal precipitation activities occur over the south TIO in the decay phase of ENSO. The difference of models from the observed SSHa may be related to the simulation of seasonal cycle of the thermocline depth and anti-cyclonic atmospheric circulation in the south TIO. For the models without robust Rossby wave propagation, the precipitation anomalies are not well simulated in location, phase, or amplitude, implying the importance of ocean dynamics for climate in the south TIO. An exception is GFDL-ESM2M, in which Rossby wave shows no propagation but air-sea interaction is among the most pronounced in all the models. The significant thermocline deepening in GFDL-ESM2M is due to the strong forcing by the in-situ anti-cyclonic atmospheric circulation. Consistently, abnormal precipitation in GFDL-ESM2M occupies the entire south TIO during February-June(1). This process suggests that the change in the thermocline ridge can be caused either by the incoming Rossby wave adjustment or the local wind curls. The thermocline ridge is fundamental to the ocean-induced atmospheric change over the south TIO. Figure 9 shows that in models the SST warming appears in the upwelling season of the thermocline. Most of models shows a close relationship between SSTa and SSHa in the SWIO during MAM(1) (Figures 10 and 11). Only a few models have problem in this SST-thermocline feedback, either without showing a depressed thermocline following El Niño or mismatched anomalies in location or phase (e.g. BCC-CSM1.1; Figure 8).

\section{e. WES Feedback and anti-symmetric atmospheric circulation}

In the boreal spring following El Niño, the increased SST warming intensifies convection thus precipitation over the south TIO, particularly in the west (Figure 11), whereas the SST warming weakens and precipitation decreases to the north over the NIO and SCS. Consistent with the SST and convection pattern, surface wind anomalies feature an anti-symmetric circulation structure, with northeasterlies north and northwesterlies south of the equator. This C-shaped wind pattern is a result of the Coriolis force acting on the northerly cross-equatorial winds to induce an easterly (westerly) component north (south) of the equator. 
Previous studies suggested that the anti-symmetric atmospheric circulation pattern results from WES feedback in the TIO (Kawamura et al. 2001; Wu et al. 2008; Du et al. 2009). The WES feedback helps to maintain an meridional SST gradient across the equator under the favorable easterly background wind (Xie and Philander 1994). During the early spring over the SWIO thermocline ridge, the northwesterly anomalies weaken the prevailing southeasterly trade winds, sustaining the SST warming. In the NIO the northeasterly anomalies, as part of the WES mode north of the equator, strengthen the northeasterly background wind and contribute to the reduction of the SST warming over the Arabian Sea (Du et al. 2009).

Some CMIP5 models suggest that the anti-symmetric atmospheric circulation is forced by anomalous positive SST and enhanced convection in the south TIO (Figure 11; e.g. GFDL-ESM2G, HadGEM2-CC), which in turn are maintained by the deepened thermocline ridge (Figures 8 and 11), as in observations. In a few other models, the wind anomalies are easterly in the eastern/southeastern equatorial Indian Ocean (Figure 11) due to the El Niño-induced Walker Circulation slowdown, obscuring the C-shaped wind (Figure 12). 8 out of 20 models present the relationship between anti-symmetric SST and wind anomalies across the equator (Figure 12, upper-right quadrant), indicating a WES feedback. The wind circulation pattern is anti-cyclonic south of the equator (Figure 11), forcing SSHa/thermocline depth anomalies (Figure 8). The anti-cyclonic wind circulation reduces the upwelling over the thermocline ridge, sustaining the SST warming (Figures 9, 10, and 11).

\section{f. NIO second warming and anti-cyclonic atmospheric circulation over NWP}

In the NIO and SCS, wind anomalies remain northeasterly till early summer following El Niño. Due to the mean winds change from northeasterly to southwesterly in April-May, the northeasterly anomalies weaken the summer monsoonal winds, reducing the release of latent heat flux in favor of the SST warming in JJA(1) (Figure 13). On the other hand, the change of upwelling further amplifies the SST warming in the west Arabian Sea (Izumo et al. 2008) and west SCS (Xie et al. 2003; Jing et al. 2011). The SWIO SST warming weakens as the Rossby wave propagates to the west boundary region and decays. The most pronounced atmospheric anomalies are the anti-cyclonic circulation over the NWP. Xie et al. (2009) showed that the TIO warming impacts on the NWP through the baroclinic atmospheric Kelvin wave from the TIO. In the NWP, this equatorial Kelvin wave induces atmospheric divergence near the surface north of the equator and 
thus triggers suppressed convection and the anomalous anti-cyclonic atmospheric circulation in the summer following El Niño.

In 15 out of 20 models the SST warming in $\mathrm{AMJ}(1)$ is related to the reduction of the southwest monsoonal wind in the NIO (Figure 14a). Note the weakening winds further reduce the Ekman transport and upwelling, especially in the Somali coastal region (Izumo et al 2008). The reduction of latent heat flux release is highly correlated with the SST warming in the NIO in 11 models, due to the reduced monsoonal winds, especially the zonal wind component (Fig. 14b-c). Most models reproduce the NIO warming and anomalous NWP anti-cyclonic circulation in JJA(1) (Figure 13), suggestive of their connection. Half of the models simulate the contrast between the negative SLP in TIO and positive SLP anomalies in NWP as in observations. The increase in precipitation in TIO forces a Kelvin wave response with low pressure and easterly wind anomalies along the equator, which triggers a reduction in precipitation and the formation of the anti-cyclonic circulation over the NWP. Previous model experiments (Xie et al. 2009) showed that the SSTa over the NIO are important to the position and pattern of the anomalous anti-cyclonic circulation over the NWP.

\section{g. Time-latitude variations along 10}

Figure 15 shows the Hovmöller diagram of SST, wind, and SLP for observations and models. Data are zonally averaged in $40^{\circ} \mathrm{E}-80^{\circ} \mathrm{E}$ to avoid large diversity among models over the east $\mathrm{TIO}$. Similar to observations, the simulated SST warming persists for nearly ten months from December(0) to August(1). In NIO, simulated SST warming decays faster than observations and is mostly confined south of $15^{\circ} \mathrm{N}$ whereas it extends to $25^{\circ} \mathrm{N}$ in observations. The SST warming in the south Indian Ocean is much stronger in model. The easterly wind anomaly along the equator is stronger in models, indicative of the reduced Walker Circulation and over-extended anti-cyclonic wind circulation in the south TIO in the CMIP5 models (Figs. 6 and 7). The anomalous anti-asymmetric wind in boreal spring is weak in models. The negative anomaly in SLP appear twice in observations, in October-November(0) and April-September(1) whereas it only occurs once in August-September(1) in models. The northward propagating tendency of SST, wind, and SLP in observations is not obvious in some of the models. ACCESS1.0, CanESM2, GISS, GFDL, IPSL, and MPI-ESM-LR models show such a northward propagation. 


\section{Discussion}

ENSO exhibits variations on decadal time scales (e.g. D'Arrigo et al. 2005; Bunge and Clarke 2009). The coral proxy data and tree-ring records (Urban et al. 2000; Li et al. 2011) and in situ SST observations (e.g. Bunge and Clarke 2009) since the 1870s illustrate the change of frequency and strength of ENSO on long time scales. The coral proxy data show that ENSO variability intensifies with shorter-period $<2.9$ years from the late nineteenth to the early twentieth century, weakens with 5-7 years during the 1920s-50s period, and enhances again and features a period of $\sim 4$ years after the 1960s (Urban et al. 2000). The RMS variance in 21 years sliding window exhibits amplitude changes in the 1920s and 1960s (Figure 16). ENSO regains the strength in the late 1970s, which is comparable to the early 1900s, consistent with previous studies (e.g. An and Wang, 2000). Although the sparse sampling and noise level bring uncertainty in low frequency variations before 1950s (e.g. Gershunov et al. 2001), the independent works support the existence of decadal modulations of the strength of ENSO (e.g. Urban et al. 2000; Bunge and Clarke 2009; Deser et al. 2010). In the entire instrumental record, ENSO is phase-locked to the NDJ(0/1) season. Studies based on the CMIP3 product suggested that the recent energetic ENSO may be related to the global warming, as the Pacific changes toward warmer and wetter conditions (Meehl et al. 2007). The change reflects a shift to a lower mean Southern Oscillation index (SOI) value and a flattening thermocline in the equatorial Pacific (Power and Smith, 2007; Yeh et al. 2009), due to the weakening of Walker Circulation along the equatorial Pacific (Vecchi et al. 2006; Tokinaga et al. 2012). A subject of debate, the enhanced warming in the Pacific Ocean, common to model projections of future climate (e.g. Liu et al. 2005; Xie et al. 2010; Meehl et al. 2007), remains to be validated by instrumental and paleo-climate observations (e.g. Collin et al. 2010). In particular, high-quality observations suggest an intensification of the Walker circulation and a La Nina-like SST trend in recent two decades (Feng et al. 2011; Merrifield and Maltrud 2011; Li and Ren 2012), probably due to a rapid warming in the Indian Ocean (Luo et al. 2012)

Global coupled GCMs simulate strong inter-decadal to centennial modulations of ENSO (e.g. Wittenberg, 2009). Indeed, in CMIP5, many models display multi-decadal variability in ENSO amplitude, but the phases are not consistent with observations, suggesting the importance of internal variability. Figures 16-17 show results from four representative models.

The multi-decadal ENSO modulations affect the IOB variance. Xie et al. (2010) found that the 
IOB mode intensifies after the decadal shift in the mid-1970s. Figure 16 confirms it and shows another IOB intensification in the late nineteenth to early twentieth century (Chowdary et al., 2012), though the data sampling is limited in the early period. In those four models, the ENSO amplitude determines IOB variance (Figure 16).

The ENSO-IOB correlations vary on inter-decadal time scales (Figure 17), related to the strength and persistence of ENSO. In observations, ENSO amplitude is the weakest during 1940s-60s, when the IOB correlation with ENSO is the smallest. Figure 18a illustrates the relationship between ENSO amplitude and ENSO-IOB correlation in JJA(1) season during the entire period of the historical run. Increased ENSO variance corresponds to an enhanced ENSO-IOB correlation in models (Figure 18a). A similar relationship exists for the IOD response to ENSO decadal modulations (Izumo et al. 2013). For each model, the decade with the maximum correlation is compared with the decade with the minimum correlation (Figure 18b). In almost all models, the correlation is low when ENSO variance is low, suggesting that the ENSO variances control the ENSO-IOB correlation in JJA(1) season. The relationship between IOB and ENSO strength is not only confirmed in inter-model difference (Figure 18a) but also in each individual model (Figure 18b). The result also demonstrates the model diversity in simulating the natural decadal variability.

We examine the inter-decadal variations of the IOB mode in further detail, using GFDL-ESM2G. Figure 19 shows the IOB evolution in three epochs, according to the decadal variation in TIO warming (Figure 17). A late TIO warming in 1956-75 results from a strong cooling in the SEIO in $\operatorname{DJF}(0 / 1)$ season, related to the strong anti-cyclonic circulation over the SEIO. In epochs of 1926-1955 and 1975-2005, the meridionally anti-symmetric wind anomalies are well developed in MAM(1). The IO warming in those epochs have different impacts on the NWP anti-cyclonic circulation during the subsequent summer. The strong anti-cyclonic circulation during JJA(1) in 1976-2005 is associated with the warming in the Bay of Bengal and South China Sea, while the atmospheric anomalies are weak in 1926-1955, as the NIO warming is weak. The differences in three epochs illustrate the role of low frequency ENSO modulation in TIO and NWP climate variation. A companion work discusses show modulation of NWP climate variability in detail (Hu et al., 2013) 


\section{Summary}

We have evaluated the IOB mode simulation in 20 CMIP5 models against observations. In 16 out of 20 models, IOB is well simulated. Among them, the IOB mode contributes about $22-49 \%$ RMS variance (40\% in observations). In most models, the IOB mode is highly correlated with ENSO. The IOB mode in the MME starts from November(0) of the ENSO developing year [October(0) in observations], and terminates roughly the same time as in observations [August(1)], with 0-3 months variations in timing in individual models. The north Indian Ocean (NIO) warming can persist into the summer following El Niño. CMIP5 simulations show that the TIO warming is not uniform but has a pronounced geographic distribution, a feature not well documented before but consistent with observations. Ours represents the first CMIP study examining the development of IOB's geographic patterns that are due to local ocean-atmosphere interactions.

Some models simulate the anti-symmetric atmospheric circulation across the equator in boreal spring, a key aspect of IOB development. The anti-symmetric atmosphere anomalies peak in MAM(1) but may delay by 1-2 months in some models. South TIO SST is the forcing of this atmospheric pattern in observations, triggered by the oceanic Rossby wave forced in prior seasons over the central and eastern TIO. In most CMIP5 models, the anomalous wind forcing covers the full zonal extent of the south TIO. For models without a clear Rossby wave propagation, the in-situ anomalous wind curls deepen the thermocline to sustain the SST warming in the south TIO.

SSTa over NIO persist into summer. In some models, the SST warming over the NIO and South China Sea exhibits a second peak in the El Niño decay summer, suggesting the effect of TIO-atmosphere interaction. In most models, the NIO warming in summer is associated to reduced surface heat flux out of the ocean associated with the reduced southwest monsoonal wind, a result consistent with the previous heat budget analysis in observations (Du et al. 2009). A further heat budget analysis is required in the future to quantify this effect compared to other possible factors in CMIP5 models. Particularly, there might be regional differences among NIO sub-basins (Montégut et al. 2007). Accompanied with the NIO warming is an anomalous anti-cyclonic atmospheric circulation over NWP, together forming the robust climatic anomalies in summer following El Niño, consistent with previous studies (e.g. Xie et al., 2009; Huang et al., 2010). The formation of the NWP anti-cyclonic circulation and its relationship to NIO warming in CMIP5 models are investigated in a companion study (Hu et al, 2013). 
As in observations, the IOB mode and its correlation with ENSO display inter-decadal variations in CMIP5 models. IOB variance responds to ENSO amplitude modulations in the Pacific. Specifically in summer following ENSO, the IOB mode and its capacitor effect on NWP climate strengthen when ENSO is vigorous and are insignificant when ENSO is weak.

The simulation of the IOB mode and key processes in CMIP5 models is good overall. Our analysis suggests that this may due partly to the improvements in simulating ENSO (Bellenger et al. 2013) and its teleconnections. This is encouraging as ENSO is an important source of seasonal predictability. In the summer following ENSO specifically, the IOB mode and capacitor effect hold key to climate variability and predictability for the NWP and highly populated East Asia (Chowdary et al. 2010, 2011).

\section{Acknowledgements:}

We wish to thank Y. Wu of LTO/SCSIO for helps in downloading and processing CMIP5 data. We acknowledge the WCRP Working Group on Coupled Modelling, which is responsible for CMIP5, the climate modeling groups (listed in Table 1 of this paper) for producing and making available their model output, and thank the U.S. Department of Energy's Program for Climate Model Diagnosis and Intercomparison (PCMDI) for providing coordinating support and organizing the analysis activity in partnership with the Global Organization for Earth System Science Portals. The satellite merged SSH data, SODA reanalysis, and ERSST were obtained from APDRC, University of Hawaii (http://apdrc.soest.hawaii.edu), HadISST and HadSST3 from the Met Office Hadley Centre (http://www.metoffice.gov.uk). This work is supported by MoST (2012CB955603, 2010CB950302), CAS (XDA05090404), NSFC (41176024, 41106010), LTO (LTOZZ1202), NSF, and JAMSTEC.

\section{References:}

Allan, R., and T. Ansell, 2006: A New Globally Complete Monthly Historical Gridded Mean Sea Level Pressure Dataset (HadSLP2): 1850-2004. J. Clim., 19, 5816-5842.

Alexander, M. A., I. Blade, M. Newman, J. R. Lanzante, N.-C. Lau, and J. D. Scott, 2002: The atmospheric bridge: The influence of ENSO teleconnections on air-sea interaction over the global oceans, J. Clim., 15, 2205-2231.

An, S. I., and F.-F. Jin, 2004: Nonlinearity and asymmetry of ENSO, J. Clim., 17, 2399-2412.

An, S.-I., and B. Wang, 2000: Interdecadal change of the structure of the ENSO mode and its impact on the ENSO frequency. J. Clim. 13, 2044-2055 .

Annamalai, H., P. Liu, and S.-P. Xie, 2005: Southwest Indian Ocean SST variability: Its local effect and remote influence on Asian Monsoons. J. Clim., 18, 4150-4167. 
Bellenger, H., E. Guilyardi, J. Leloup, M. Lengaigne, and J. Vialard, 2013: ENSO representation in climate models: from CMIP3 to CMIP5, Clim. Dyn., revised.

Bunge, L., and A. J. Clarke, 2009: A verified estimation of the El Niño index Niño-3.4 since 1877. $J$. Clim., 22, 3979-3992.

Carton, J. A., and B. S. Giese, 2008: A reanalysis of ocean climate using Simple Ocean Data Assimilation (SODA). Mon. Wea. Rev., 136, 2999-3017.

Chowdary, J. S., S.-P. Xie, J.-Y. Lee, Y. Kosaka, and B. Wang, 2010: Predictability of summer Northwest Pacific climate in eleven coupled model hindcasts: Local and remote forcing. $J$. Geophys. Res.-Atmos., 115, D22121, doi:10.1029/2010JD014595.

Chowdary, J. S., S.-P. Xie, J.-J. Luo, J. Hafner, S. Behera, Y. Masumoto, and T. Yamagata, 2011: Predictability of Northwest Pacific climate during summer and the role of the tropical Indian Ocean. Clim. Dyn., 36, 607-621, doi:10.1007/s00382-009-0686-5.

Chowdary, J. S., S.-P. Xie, H. Tokinaga, Y. M. Okumura, H. Kubota, N. C. Johnson, and X.-T. Zheng, 2012: Inter-decadal variations in ENSO teleconnection to the Indo-western Pacific for 1870-2007. J. Climate, 25, 1722-744.

Collins, M., S.-I. An, W. Cai, A. Ganachaud, E. Guilyardi, F.-F. Jin, M. Jochum, M. Lengaigne, S. Power, A. Timmermann, G. Vecchi, and A. Wittenberg, 2010: The impact of global warming on the tropical Pacific Ocean and El Niño. Nature Geoscience, 3, 391-397.

D'Arrigo, R., E. Cook, R. Wilson, R. Allan, and M Mann, 2005: On the variability of ENSO over the past six centuries. Geophys. Res. Lett., 32, L03711.

Deser, C., A. S. Phillips, and M. A. Alexander, 2010: Twentieth century tropical sea surface temperature trends revisited, Geophys. Res. Lett., 37, L10701, doi:10.1029/2010GL043321.

Du, Y., T. Qu, G. Meyers, Y. Masumoto, and H. Sasaki, 2005: Seasonal heat budget in the mixed layer of the southeastern tropical Indian Ocean in a high-resolution ocean general circulation model. J. Geophys. Res., 110, C04012, doi, 10.1029/2004JC002845.

Du, Y., T. Qu, G. Meyers, 2008: Interannual variability of the sea surface temperature off Java and Sumatra in a global GCM. J. Clim., 21, 2451-2465.

Du, Y., S.-P. Xie, K. Hu, and G. Huang, 2009: Role of Air-Sea Interaction in the Long Persistence of El Niño-Induced North Indian Ocean Warming, J. Clim., 22, 2023-2038.

Du, Y., L. Yang, and S.-P. Xie, 2011: Tropical Indian Ocean Influence on Northwest Pacific Tropical Cyclones in Summer Following Strong El Niño. J. Clim., 24, 315-322.

Feng, M., C. Böning, A. Biastoch, E. Behrens, E. Weller, and Y. Masumoto, 2011: The reversal of the multi-decadal trends of the equatorial Pacific easterly winds, and the Indonesian Throughflow and Leeuwin Current transports, Geophys. Res. Lett., 38, L11604, doi:10.1029/2011GL047291.

Fisher, R. A., 1921, On the "probable error" of a coefficient of correlation deduced from a small sample, Metron, 1, 3-32.

Gershunov, A., N. Schneider, and T. Barnett, 2001: Low frequency modulation of the ENSO-Indian monsoon rainfall relationship: Signal or noise? J. Clim., 14, 2486-2492. 
Guilyardi, E., 2006: El Niño-mean state-seasonal cycle interactions in a multi-model ensemble. Clim. Dyn., 26, 329-348.

Hermes, J., and C. J. C. Reason, 2008: Annual cycle of the south Indian Ocean (Seychelles-Chagos) thermocline ridge in a regional ocean model, J. Geophys. Res., 107, C04035, doi:10.1029/2007JC004363.

Li G., B. Ren, 2012: Evidence for strengthening of the tropical Pacific Ocean surface wind speed during 1979-2001, Theor. Appl. Climatol., 107, 59-72.

$\mathrm{Hu}, \mathrm{K}$., et al., Interdecadal variations in ENSO's influences on western North Pacific and East Asia summertime climate simulated in the CMIP5 models. J. Clim. 2013, in prep.

Huang, G., K. Hu, and S. P. Xie, 2010: Strengthening of Tropical Indian Ocean Teleconnection to the Northwest Pacific since the Mid-1970s: An Atmospheric GCM Study. J Clim., 23, 5294-5304.

Izumo, T., C. de Boyer Montegut, J.-J. Luo, S. K. Behera, S. Masson, and T. Yamagata, 2008: The role of the western Arabian Sea upwelling in Indian monsoon rainfall variability, J. Clim., 21, 5603-5623.

Izumo, T., M. Lengaigne, J. Vialard, J.-J. Luo, T. Yamagata, G. Madec, 2013: Influence of Indian Ocean Dipole and Pacific recharge on following year's El Niño: interdecadal robustness, Clim. Dyn., in press, doi:10.1007/s00382-012-1628-1.

Jing, Z., Y. Qi, and Y. Du, 2011: Upwelling in the continental shelf of northern South China Sea associated with 1997-1998 El Niño, J. Geophys. Res., 116, C02033, doi:10.1029/2010JC006598.

Kanamitsu, M., W. Ebisuzaki, J Woollen, S.-K. Yang, J. J. Hnilo, M. Fiorino, and G. L. Potter, 2002: NCEP-DOE AMIP-II Reanalysis (R-2), Bull. Amer. Meteor. Soc., 83, 1631-1643.

Kawamura, R., T. Matsumura, and S. Iizuka, 2001: Role of equatorially asymmetric sea surface temperature anomalies in the Indian Ocean in the Asian summer monsoon and El Niño-Southern Oscillation coupling, J. Geophys. Res., 106, 4681-4693.

Kennedy, J.J., N.A. Rayner, R.O. Smith, M. Saunby, and D.E. Parker, 2011: Reassessing biases and other uncertainties in sea-surface temperature observations since 1850 part 1: measurement and sampling errors, J. Geophys. Res., 116, D14103, doi:10.1029/2010JD015218.

Klein, S. A., B. J. Soden, and N.-C. Lau, 1999: Remote sea surface temperature variations during ENSO: Evidence for a tropical atmospheric bridge, J. Clim., 12, 917-932.

Kug, J.-S., S.-I. An, F.-F. Jin, I-S. Kang, 2005: Preconditions for E1 Niño and La Niña onsets and their relation to the Indian Ocean, Geophys. Res. Lett., 32,

L05706,doi:10.1029/2004GL021674.

Lau, N.-C., and M. J. Nath, 2003: Atmosphere-ocean variations in the Indo-Pacific sector during ENSO episodes, J. Clim., 16, 3-20.

Li, J., S.-P. Xie, E. R. Cook, G. Huang, R. D'Arrigo, F. Liu, J. Ma and X. Zheng, 2011: Interdecadal modulation of El Niño amplitude during the past millennium. Nature Climate Change, $\mathbf{1}$, 114-118, doi:10.1038/nclimate1086.

Liu, Z., S. Vavrus, F. He, N. Wen, and Y. Zhong, 2005: Rethinking tropical ocean response to global 
warming: The enhanced equatorial warming, J. Climate, 18, 4684-4700.

Masson, S. and Coauthors, 2005: Impact of barrier layer on winter-spring variability of the southeastern Arabian Sea, Geophys. Res. Lett., 32, L07703, doi: 10.1029/2004GL021980.

Masumoto, Y., and G. Meyers, 1998: Forced Rossby waves in the southern tropical Indian Ocean, $J$. Geophys. Res., 103, 27 589-27 602.

Meehl, G. A., and Coauthors, 2007: Global climate projections. Climate Change 2007: The Physical Science Basis, Contribution of Working Group I to the Fourth Assessment Report of the Intergovernmental Panel on Climate Change. S. Solomon et al., Eds., Cambridge University Press, 747-845.

Merrifield, M. A., and M. E. Maltrud, 2011: Regional sea level trends due to a Pacific trade wind intensification, Geophys. Res. Lett., 38, L21605, doi:10.1029/2011GL049576.

Montégut, C. B., J. Vialard, S. S. C. Shenoi, D. Shankar, F. Durand, C. Ethé, G. Madec, 2007: Simulated Seasonal and Interannual Variability of the Mixed Layer Heat Budget in the Northern Indian Ocean, J. Clim., 20, 3249-3268, doi: http://dx.doi.org/10.1175/JCLI4148.1.

Murtugudde, R., J. P. McCreary, and A. J. Busalacchi, 2000: Oceanic processes associated with anomalous events in the Indian Ocean with relevance to 1997-1998, J. Geophys. Res., 105, 3295-3306.

Nicholls, N., 1984: The Southern Oscillation and Indonesian sea surface temperature. Mon. Wea. Rev., 112, 424-432.

Ohba, M., and H. Ueda, 2005: Basin-wide warming in the equatorial Indian Ocean associated with E1 Niño. SOLA, 1, 89-92.

Ohba, M., and H. Ueda, 2009: Role of nonlinear atmospheric response to SST on the asymmetric transition process of ENSO. J. Clim., 22, 177-192.

Okumura Y. M., M. Ohba, C. Deser, H. Ueda, 2011: A Proposed Mechanism for the Asymmetric Duration of E1 Niño and La Niña, J. Clim., 24, 3822-3829.

Perigaud, C., and P. Delecluse, 1993: Interannual sea level variations in the tropical Indian Ocean from Geosat and shallow-water simulations, J. Phys. Oceanogr., 23, 1916-1934.

Power, S. B., and I. N. Smith, 2007: Weakening of the Walker Circulation and apparent dominance of El Niño both reach record levels, but has ENSO really changed?, Geophys. Res. Lett., 34, L18702, doi:10.1029/2007GL030854.

Qu, T., and G. Meyers, 2005: Seasonal variation of barrier layer in the southeastern tropical Indian Ocean. J. Geophys. Res.-Oceans, 110, doi: C11003, 10.1029/2004JC002816.

Rayner, N. A., Parker, D. E., Horton, E. B., Folland, C. K., Alexander, L. V., Rowell, D. P., Kent, E. C., Kaplan, A., 2003: Global analyses of sea surface temperature, sea ice, and night marine air temperature since the late nineteenth century. J. Geophys. Res. 108, 4407, 10.1029/2002JD002670.

Saji,N.H., B.N.Goswami, P. N.Vinayachandran, and T. Yamagata, 1999: A dipole mode in the tropical Indian Ocean. Nature, 401, 360-363. 
Saji, N. H., S.-P. Xie, and T. Yamagata, 2006: Tropical Indian Ocean variability in the IPCC 20th-century climate simulations, J. Clim., 19, 4397-4417.

Schott, F. A., S.-P. Xie, and J. P. McCreary Jr., 2009: Indian Ocean circulation and climate variability, Rev. Geophys., 47, RG1002, doi:10.1029/2007RG000245.

Shinoda, T., M. A. Alexander, and H. H. Hendon, 2004: Remote response of the Indian Ocean to interannual SST variations in the tropical Pacific, J. Clim., 17, 362-372.

Smith, T.M., R.W. Reynolds, Thomas C. Peterson, and Jay Lawrimore, 2008: Improvements to NOAA's Historical Merged Land-Ocean Surface Temperature Analysis (1880-2006). J. Clim., 21, 2283-2296.

Taschetto, A. S., A. S. Gupta, H. H. Hendon, C. C. Ummenhofer, and M. H. England, 2011: The Contribution of Indian Ocean Sea Surface Temperature Anomalies on Australian Summer Rainfall during El Niño Events. J. Clim., 24, 3734-3747.

Taylor, K. E., R. J. Stouffer, G. A. Meehl, 2012: An Overview of CMIP5 and the Experiment Design. Bull. Amer. Meteor. Soc., 93, 485-498. doi: http://dx.doi.org/10.1175/BAMS-D-11-00094.1

Tokinaga, H., and Y. Tanimoto, 2004: Seasonal transition of SST anomalies in the tropical Indian Ocean during El Niño and Indian Ocean Dipole years, J. Meteorol. Soc. Jpn., 82, 1007-1018.

Urban, F. E., J. E. Cole, and J. T. Overpeck, 2000: Influence of mean climate change on climate variability from a 155-year tropical Pacific coral record, Nature, 407, 989-993.

Vecchi, G. A. et al., 2006: Weakening of tropical Pacific atmospheric circulation due to anthropogenic forcing, Nature, 441, 73-76.

Wallace, J. M., E. M. Rasmusson, T. P. Mitchell, V. E. Kousky, E. S. Sarachik, and H. von Storch, 1998: On the structure and evolution of ENSO-related climate variability in the tropical Pacific: Lessons from TOGA, J. Geophys. Res., 103, 241-14,259.

Wang, B., R. Wu, and T. Li, 2003: Atmosphere-warm ocean interaction and its impact on Asian-Australian monsoon variability, J. Clim., 16, 1195-1211.

Wang, B., R. Wu, and X. Fu, 2000: Pacific--east Asia teleconnection: How does ENSO affect east Asian climate? J. Clim., 13, 1517-1536.

Wang, C., and J. Picaut, 2004: Understanding ENSO physics - A review, in Earth's Climate: The Ocean-Atmosphere Interaction, Geophys. Monogr. Ser, 147, edited by C. Wang, S.-P. Xie, and J. A. Carton, AGU.

Weare, B. C., 1979: A statistical study of the relationships between ocean surface temperatures and the Indian monsoon, J. Atmos. Sci., 36, 2279-2291.

Wittenberg, A. T., 2009: Are historical records sufficient to constrain ENSO simulations? Geophys. Res. Lett., 36, L12702. doi: 10.1029/2009GL038710.

Wu, R., B. P. Kirtman, and V. Krishnamurthy, 2008: An asymmetric mode of tropical Indian Ocean rainfall variability in boreal spring, $J$. Geophys. Res., 113, D05104, doi:10.1029/2007JD009316. 
Wu, Y.-L., Y. Du, Y.-H. Zhang, X.-T. Zheng, 2012: Interannual variability of sea surface temperature in the Northern Indian Ocean associated with ENSO and IOD, Atmos. Oceanic Sci. Lett., 5, 295-300.

Xie, S.-P., and S. G. H. Philander, 1994, A coupled ocean-atmosphere model of relevance to the ITCZ in the eastern Pacific, Tellus, Ser. A., 46, 340-350.

Xie, S.-P., H. Annamalai, F. Schott, and J. P. McCreary Jr, 2002: Origin and predictability of South Indian Ocean climate variability, J. Clim., 15(8), 864-874.

Xie, S.-P., Q. Xie, D. X. Wang, and W. T. Liu, 2003: Summer upwelling in the South China Sea and its role in regional climate variations, J. Geophys. Res., 108, 3261, doi:10.1029/2003JC001867.

Xie, S.-P., K. Hu, J. Hafner, H. Tokinaga, Y. Du, G. Huang, and T. Sampe, 2009: Indian Ocean capacitor effect on Indo-western Pacific climate during the summer following El Niño, J. Clim., 22, 730-747.

Xie, S.-P., C. Deser, G.A. Vecchi, J. Ma, H. Teng, and A.T. Wittenberg, 2010: Global warming pattern formation: Sea surface temperature and rainfall. $J$. Climate, 23, 966-986.

Xie, P.P., and P.A. Arkin, 1997: Global Precipitation: A 17-year monthly analysis based on gauge observations, satellite estimates, and numerical model outputs, Bull. Amer. Meteor. Soc., 78, 2539-2558.

Yamagata, T., S.K. Behera, J. J. Luo, S. Masson, M.R. Jury, and S.A. Rao 2004: Coupled Ocean-Atmosphere variability in the Tropical Indian Ocean, Earth's climate: The Ocean-Atmosphere Interaction. Geophys. Monogr. Ser., 147, doi:10.1029/147GM12, Eds. by Wang, C., S.-P. Xie, and J.A. Carton, AGU.

Yang, J., Q. Liu, S.-P. Xie, Z. Liu, and L. Wu, 2007: Impact of the Indian Ocean SST basin mode on the Asian summer monsoon, Geophys. Res. Lett., 34, L02708, doi:10.1029/2006GL028571.

Yeh, S.-W., J. S. Kug, B. Dewitte, M.H. Kwon, B.P. Kirtman, F.F. Jin, 2009: El Niño in a changing climate, Nature, 461, 511-4. doi:10.1038/nature08316

Yokoi, T., T. Tozuka, and T. Yamagata, 2008: Seasonal variation of the Seychelles Dome, J. Clim., 21, 3740-3754.

Yokoi, T., T. Tozuka, and T. Yamagata, 2009: Seasonal variation of the Seychelles Dome simulated in the CMIP3 models, J. Phys. Oceanogr., 39, 449-457.

Yokoi, T., T. Tozuka, T. Yamagata, 2012: Seasonal and interannual variations of the SST above the Seychelles Dome, J. Clim., 25, 800-814.

Yu, L., and M.M. Rienecker, 1999: Mechanisms for the Indian Ocean warming during the 1997-98 El Niño. Geophys. Res. Lett., 26, 735-738.

Yu, W., B. Xiang, L. Liu, and N. Liu, 2005: Understanding the origins of interannual thermocline variations in the tropical Indian Ocean, Geophys. Res. Lett., 32, L24706, doi:10.1029/2005GL024327.

Zheng, X.-T., S.-P. Xie, G. A. Vecchi, Q. Liu, and J. Hafner, 2010: Indian Ocean dipole response to global warming: Analysis of ocean-atmospheric feedbacks in a coupled model. J. Clim., 23, 1240-1253. 
Zheng, X.-T., S.-P. Xie, and Q. Liu, 2011: Response of the Indian Ocean basin mode and its capacitor effect to global warming. J. Clim., 24, 6146-6164.

Zheng, X.-T., S.-P. Xie, Y. Du, L. Liu, G. Huang, and Q. Liu, 2013, Indian Ocean Dipole response to global warming in the CMIP5 multi-model ensemble. J. Clim.. accepted.

Table 1. The WCRP CMIP5 models used in this study. In the following figures, the ensemble mean of all models marks MME (multi-model ensemble) composite.

\begin{tabular}{|c|c|c|c|c|}
\hline & Model & Source & Atmo.Res. & Ocean Res. \\
\hline 1 & ACCESS1.0 & CSIRO-BOM/Australia & $192 * 145$ & $360 * 300$ \\
\hline 2 & BCC-CSM1.1 & BCC/Canada & $128 * 64$ & $360 * 232$ \\
\hline 3 & CanESM2 & CCCma/Canada & $128 * 64$ & $256 * 192$ \\
\hline 4 & CNRM-CM5 & CNRM-CERFACS/France & $256 * 128$ & $144 * 90$ \\
\hline 5 & CSIRO-Mk3.6 & CSIRO-QCCCE/Australia & $192 * 96$ & $192 * 189$ \\
\hline 6 & FGOALS-S2 & IAP/China & $128 * 108$ & $360 * 196$ \\
\hline 7 & GFDL-ESM2G & NOAA GFDL/USA & $144 * 90$ & $360 * 210$ \\
\hline 8 & GFDL-ESM2M & NOAA GFDL/USA & $144 * 90$ & $360 * 200$ \\
\hline 9 & GISS-E2-H & NASA-GISS/USA & $144 * 90$ & $144 * 90$ \\
\hline 10 & GISS-E2-R & NASA-GISS/USA & $144 * 90$ & $144 * 90$ \\
\hline 11 & HadGEM2-CC & MOHC/UK & $192 * 145$ & $360 * 216$ \\
\hline 12 & HadGEM2-ES & MOHC/UK & $192 * 145$ & $360 * 216$ \\
\hline 13 & INMCM4 & INM/ Russia & $180 * 120$ & $360 * 340$ \\
\hline 14 & IPSL-CM5A-LR & IPSL/France & $96 * 96$ & $182 * 149$ \\
\hline 15 & IPSL-CM5A-MR & IPSL/France & $96 * 96$ & $182 * 149$ \\
\hline 16 & MIROC5 & MIROC/Japan & $256 * 224$ & $360 * 368$ \\
\hline 17 & MIROC-ESM & MIROC/Japan & $128 * 64$ & $256 * 192$ \\
\hline 18 & MPI-ESM-LR & MPI-M/Germany & $192 * 96$ & $256 * 220$ \\
\hline 19 & MRI-CGCM3 & MRI/Japan & $320 * 160$ & $360 * 368$ \\
\hline 20 & NorESM1-M & $144 * 96$ & $320 * 384$ \\
\hline
\end{tabular}




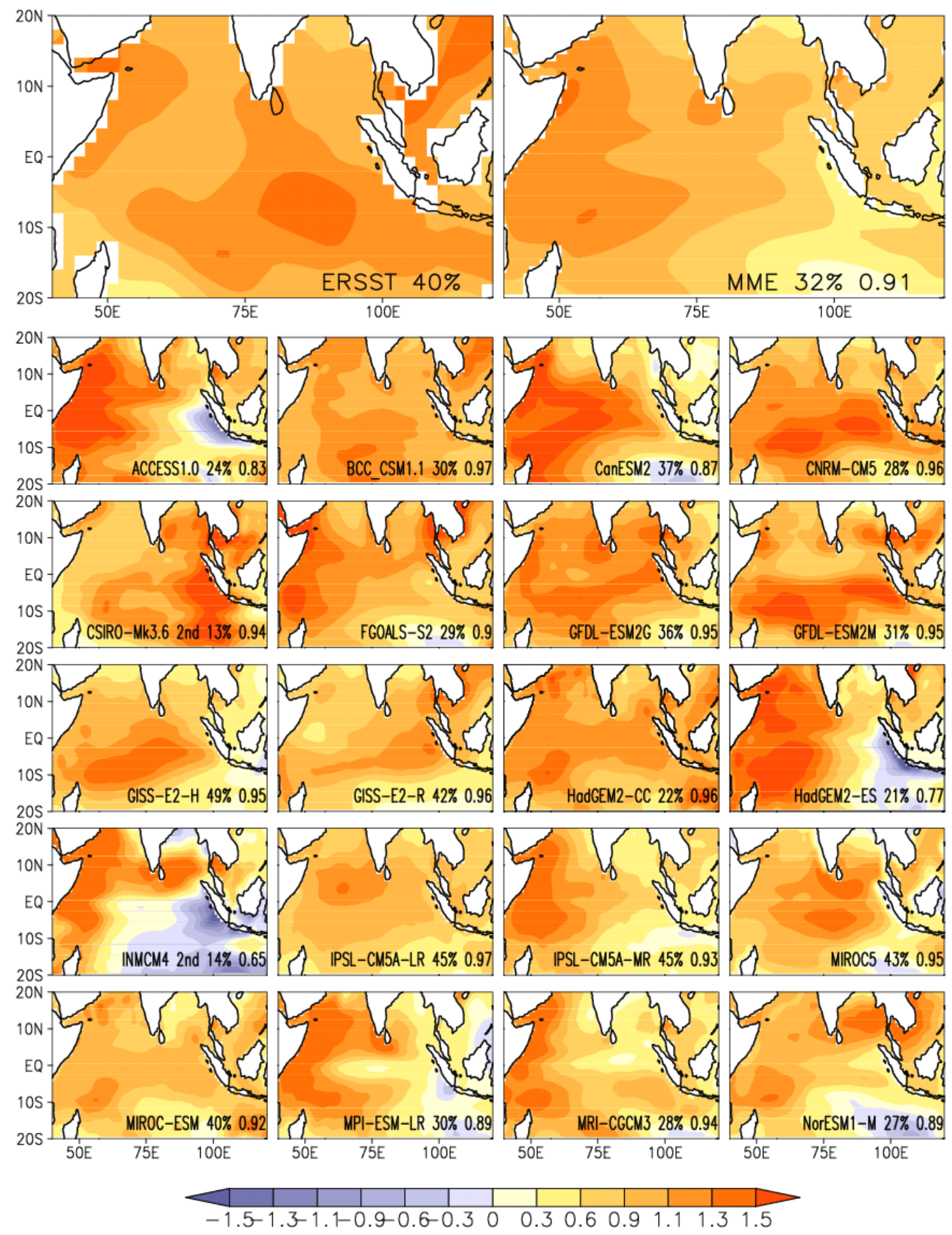

Fig. 1 First EOF modes of tropical Indian Ocean SST variability $\left({ }^{\circ} \mathrm{C}\right.$; second mode for CSIRO-Mk3.6 and INMCM4). Percentage explains variance contribution in each model. Pattern correlation coefficient between ERSST and CMIP5 SST EOF modes is included in the lower right corner of each panel. MME presents all models ensemble mean. 

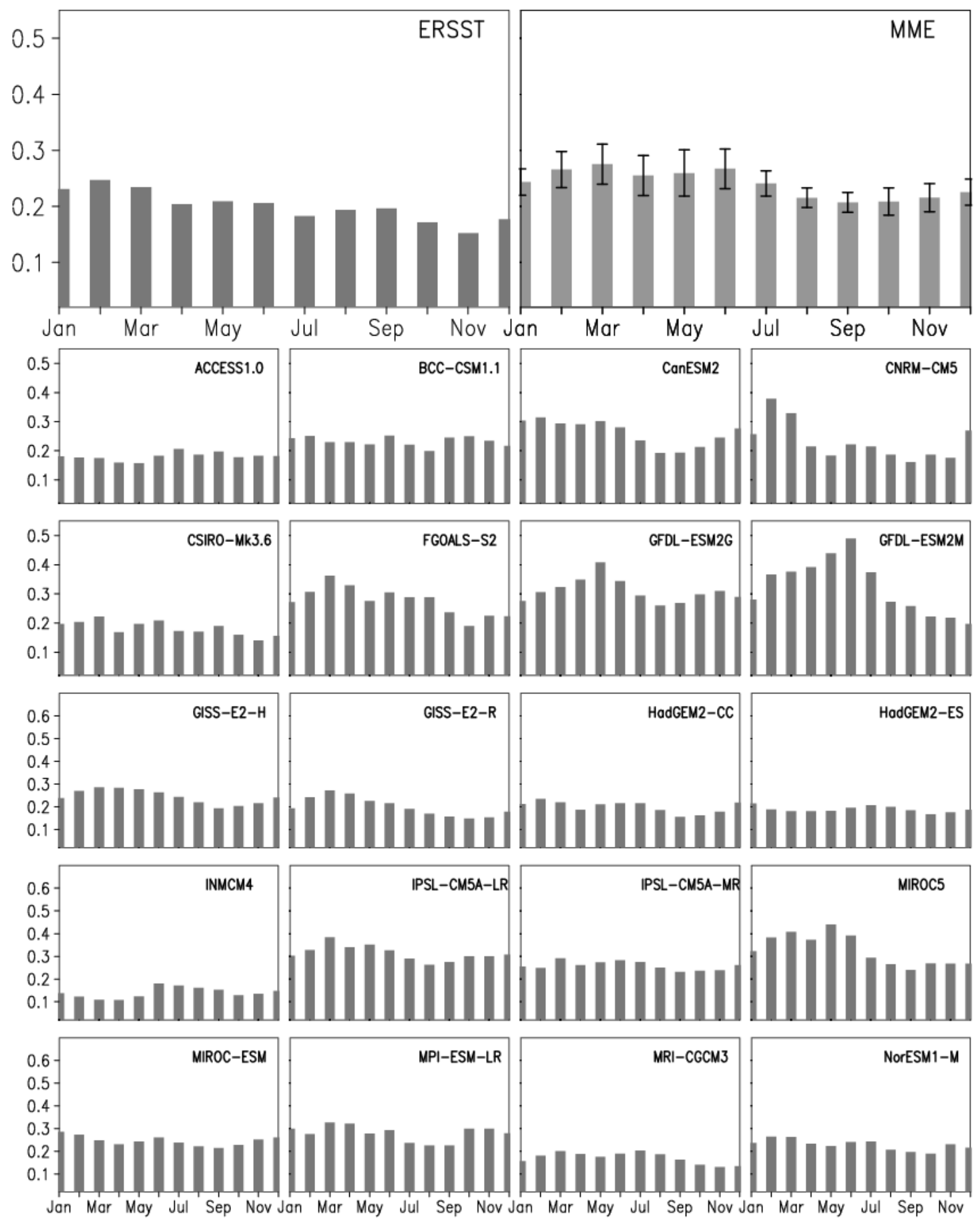

Fig. 2 Standard deviation of PC1 (PC2 in CSIRO-Mk3.6 and INMCM4) as a function of calendar month. The interval of $95 \%$ significant confidence level across the models on a $t$ test is marked in MME. 

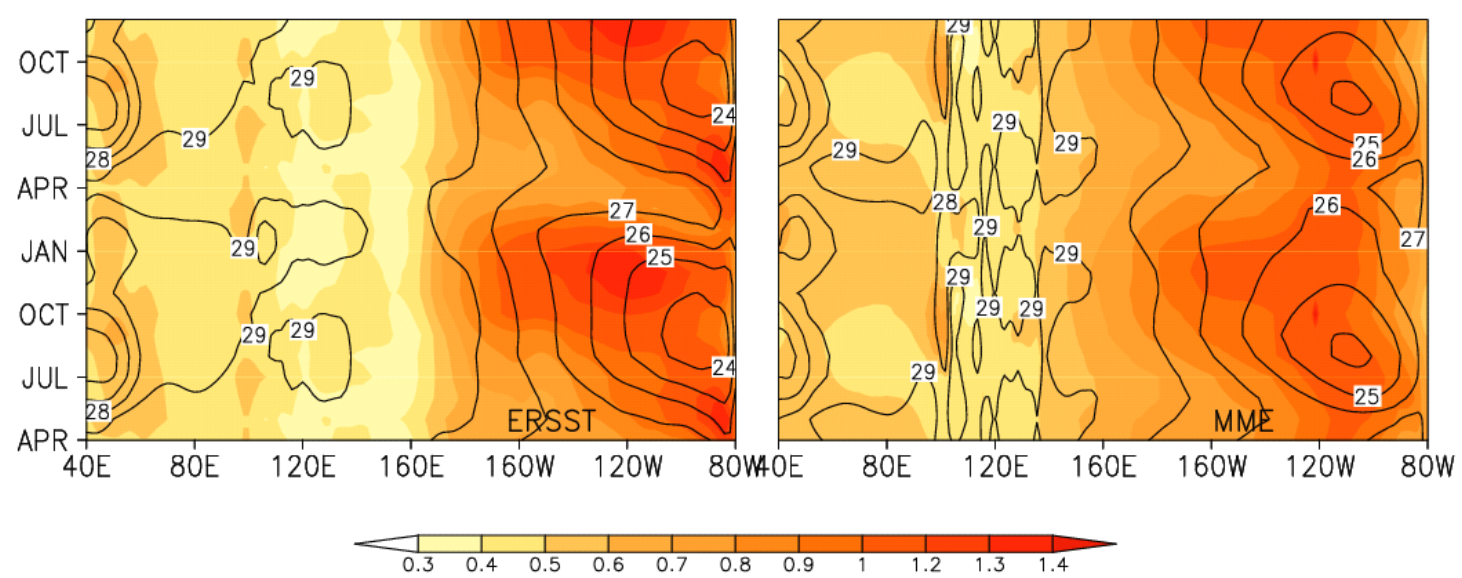

Fig. 3 Standard deviation (shading, ${ }^{\circ} \mathrm{C}$ ) of SSTa along equator, averaged in $5^{\circ} \mathrm{S}-5^{\circ} \mathrm{N}$, as a function of longitude and calendar month, superimposed with the seasonal cycle (contour, ${ }^{\circ} \mathrm{C}$ ).
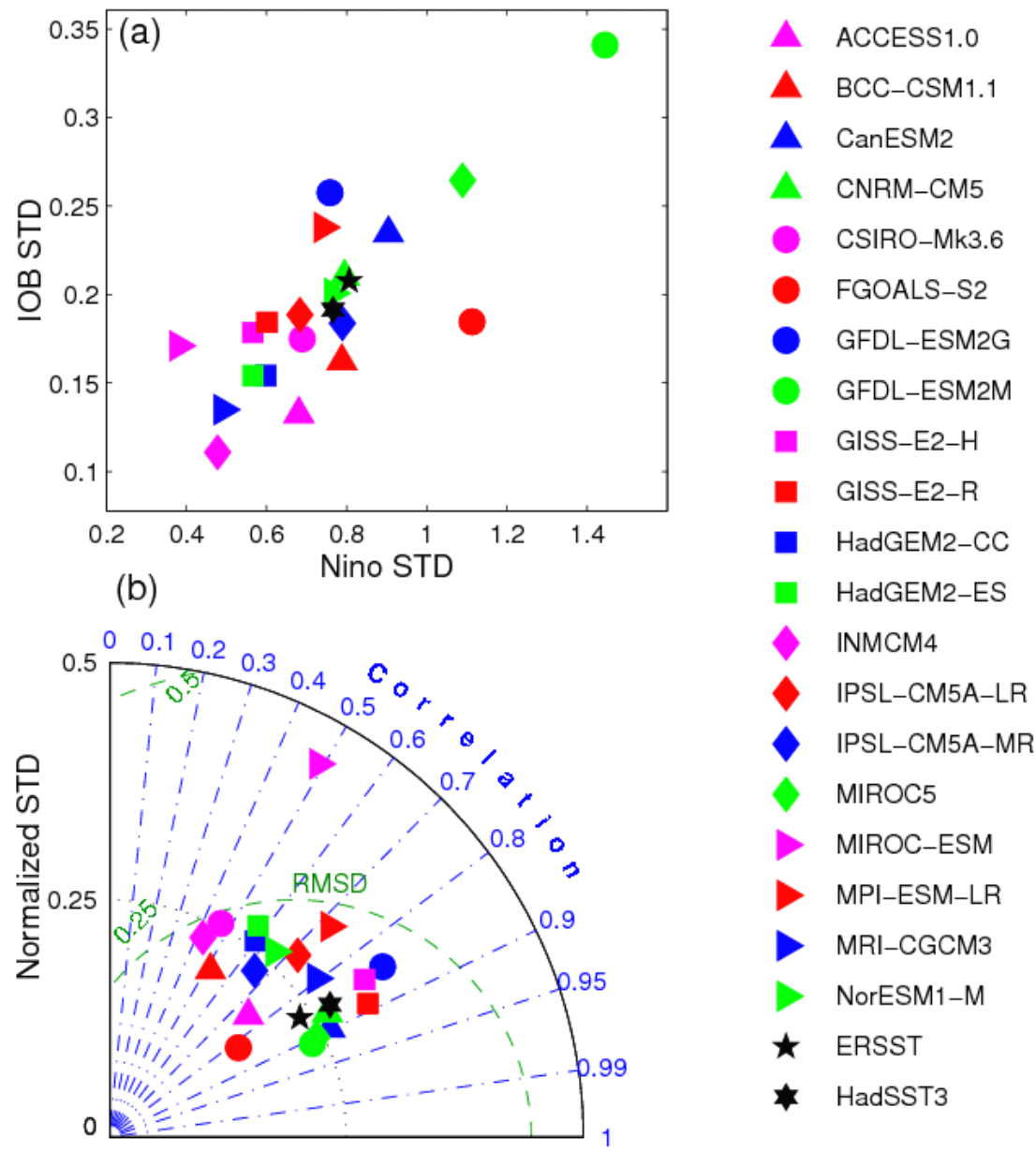

Normalized STD

Fig. 4 Relationship of IOB and ENSO: a) Scatter diagram of standard deviations (STDs) of the TIO SST $\left(20^{\circ} \mathrm{S}-20^{\circ} \mathrm{N}, 40^{\circ}-100^{\circ} \mathrm{E}\right)$ and Niño $3.4 \mathrm{SST}\left(5^{\circ} \mathrm{S}-5^{\circ} \mathrm{N}, 170^{\circ} \mathrm{W}-120^{\circ} \mathrm{W}\right)$, and b) Taylor diagram of IOB simulation. In b), the horizontal and vertical axises denote the STD of IOB. The IOB STD is normalized by the ratio of the STD of the Niño 3.4 SST index in observations (averaged of ERSST and HadSST3) to each model. The outer arc is the maximum correlation between TIO SST and Niño 3.4 NDJ(0/1) index. The green arcs denote RMS difference between the normalized IOB STD and Niño 3.4 SST STD. 

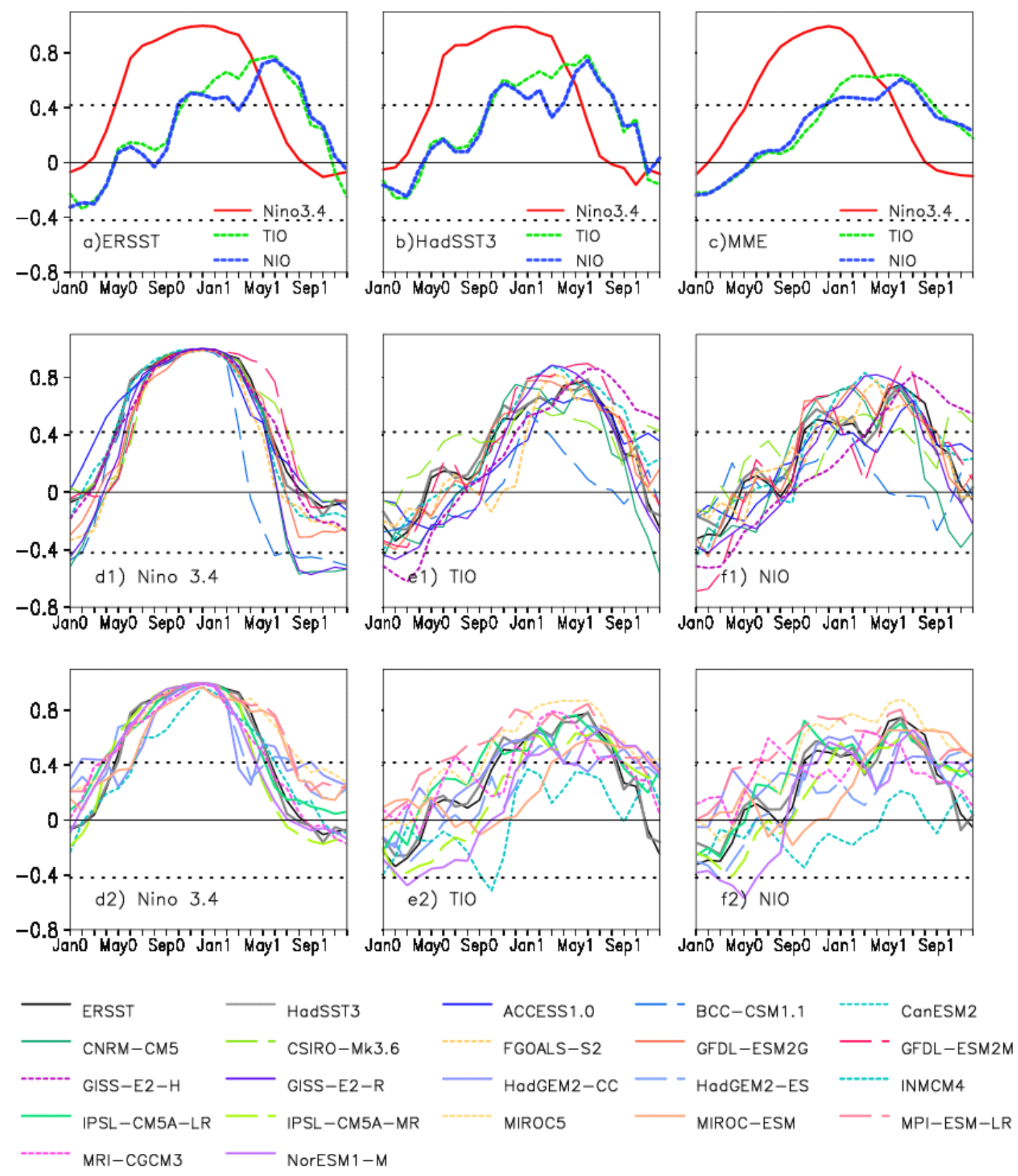

Fig. 5 Correlation of $\mathrm{NDJ}(0 / 1)$ Niño3.4 index with Niño3.4 SST $\left(5^{\circ} \mathrm{S}-5^{\circ} \mathrm{N}, 170^{\circ} \mathrm{W}-120^{\circ} \mathrm{W}\right.$, black solid line), TIO SST $\left(20^{\circ} \mathrm{S}-20^{\circ} \mathrm{N}, 40^{\circ} \mathrm{E}-100^{\circ} \mathrm{E}\right.$, green dashed line $)$, NIO SST $\left(0^{\circ}-20^{\circ} \mathrm{N}, 40^{\circ} \mathrm{E}-100^{\circ} \mathrm{E}\right.$, blue dashed line) based on the (a) ERSST, (b) HadSST3, (c) all model composite. Correlation of Niño3.4 NDJ(0/1) SST index with (d) Niño3.4 SST ( $\left.5^{\circ} \mathrm{S}-5^{\circ} \mathrm{N}, 170^{\circ} \mathrm{W}-120^{\circ} \mathrm{W}\right)$, (e) TIO SST $\left(20^{\circ} \mathrm{S}-20^{\circ} \mathrm{N}, 40^{\circ} \mathrm{E}-100^{\circ} \mathrm{E}\right)$, (f) NIO SST $\left(0^{\circ}-20^{\circ} \mathrm{N}, 40^{\circ} \mathrm{E}-100^{\circ} \mathrm{E}\right)$. Dotted black line denotes statistical significance at the $95 \%$ confidence level on a $t$ test. Figs d-f show in two panels (e.g. d1, d2) to provide better visibility. 

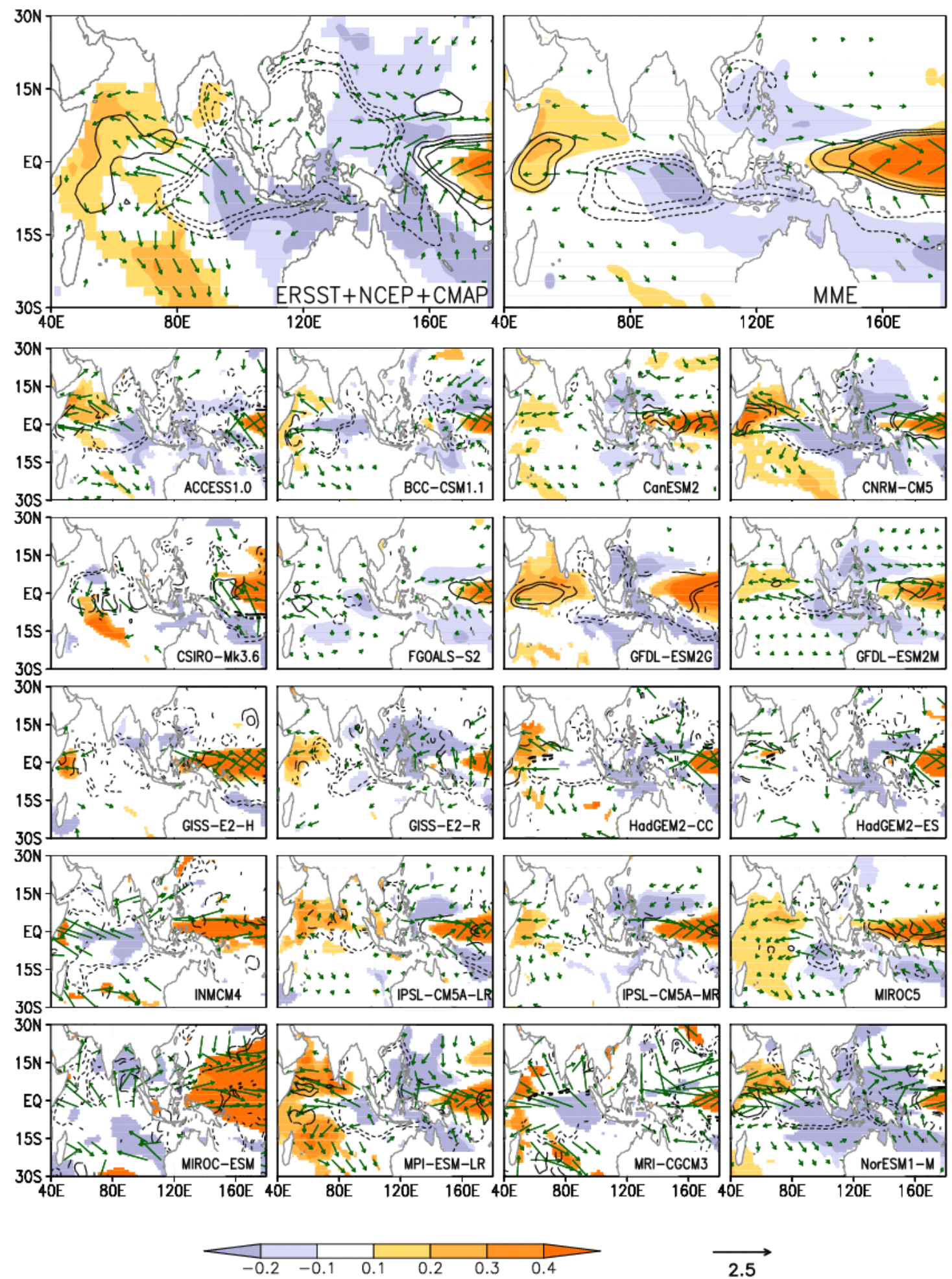

Fig. 6 Regression upon the NDJ(0/1) Niño-3.4 index for SON(0): SST (color shading, ${ }^{\circ} \mathrm{C}$ ), surface wind (vector, $\mathrm{m} / \mathrm{s}$ ), and precipitation (contour, $\mathrm{CI}=0.6 \mathrm{~mm} /$ day) over $90 \%$ confidence level on a $t$ test. 


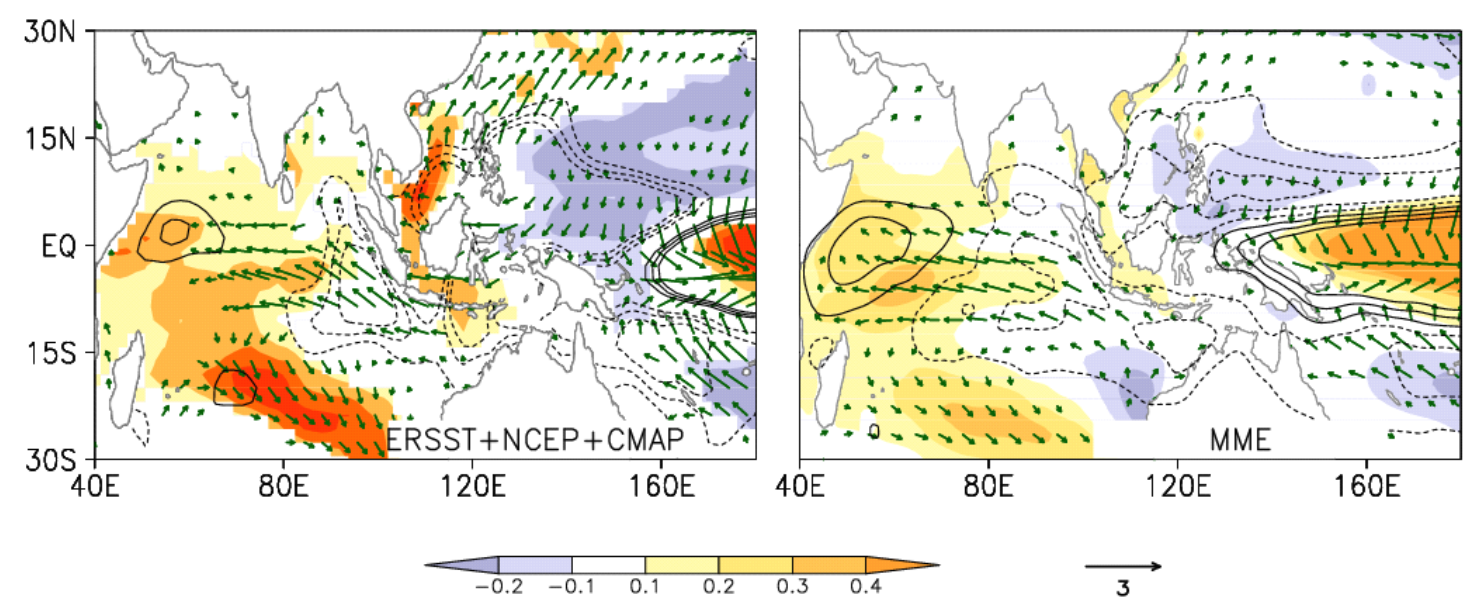

Fig. 7 Regression upon the NDJ(0/1) Niño-3.4 index for DJF(0/1): SST (color shading, ${ }^{\circ} \mathrm{C}$ ), surface wind (vector, $\mathrm{m} / \mathrm{s}$ ), and precipitation (contour, $\mathrm{CI}=0.6 \mathrm{~mm} /$ day) over $90 \%$ confidence level on a $t$ test. 


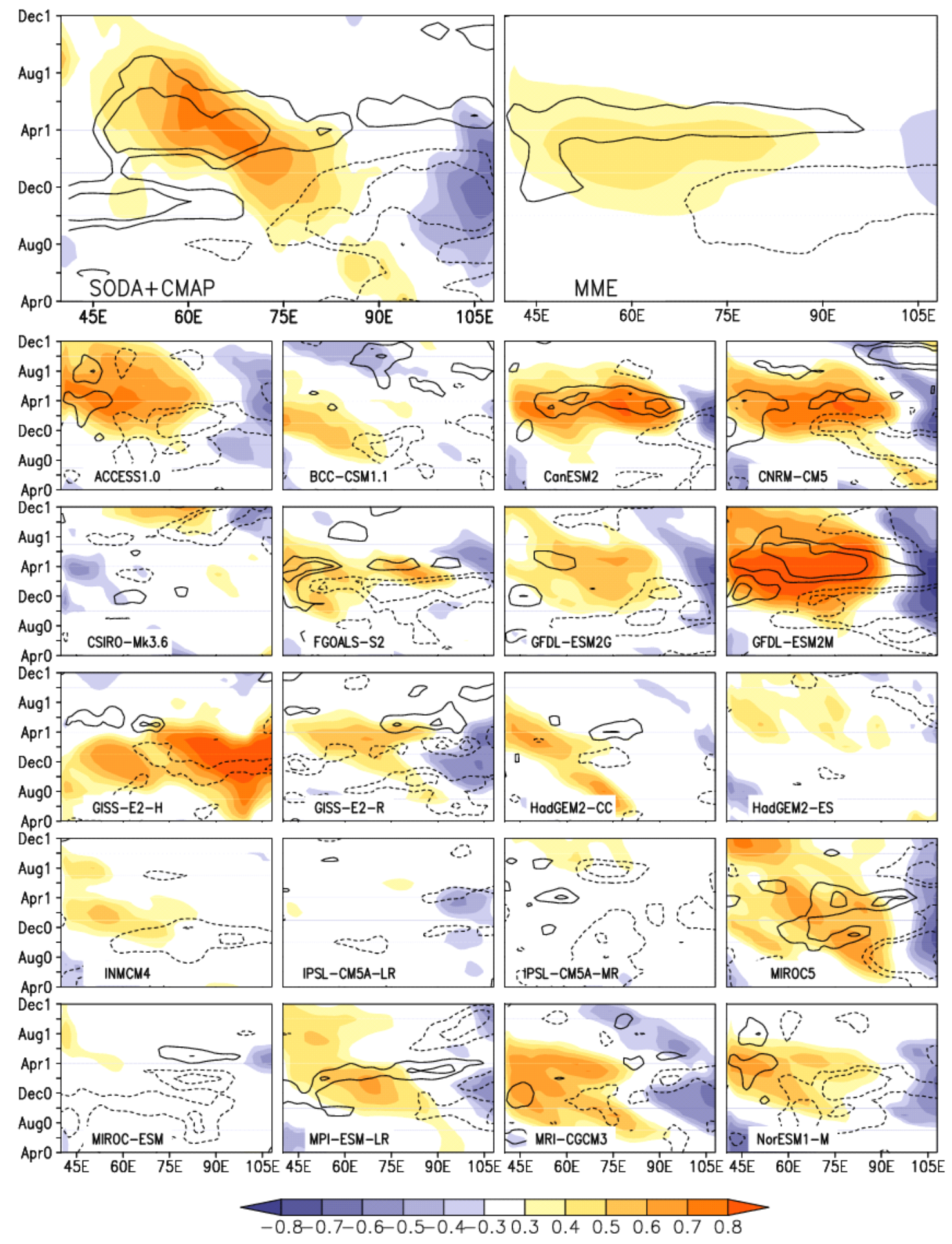

Fig. 8 Longitude-time section of correlation with the NDJ(0/1) Niño3.4 index: SSH (color shading), and precipitation (contour, $\mathrm{CI}=0.2$, from 0.4 ) averaged in $8^{\circ} \mathrm{S}-12^{\circ} \mathrm{S}$. 

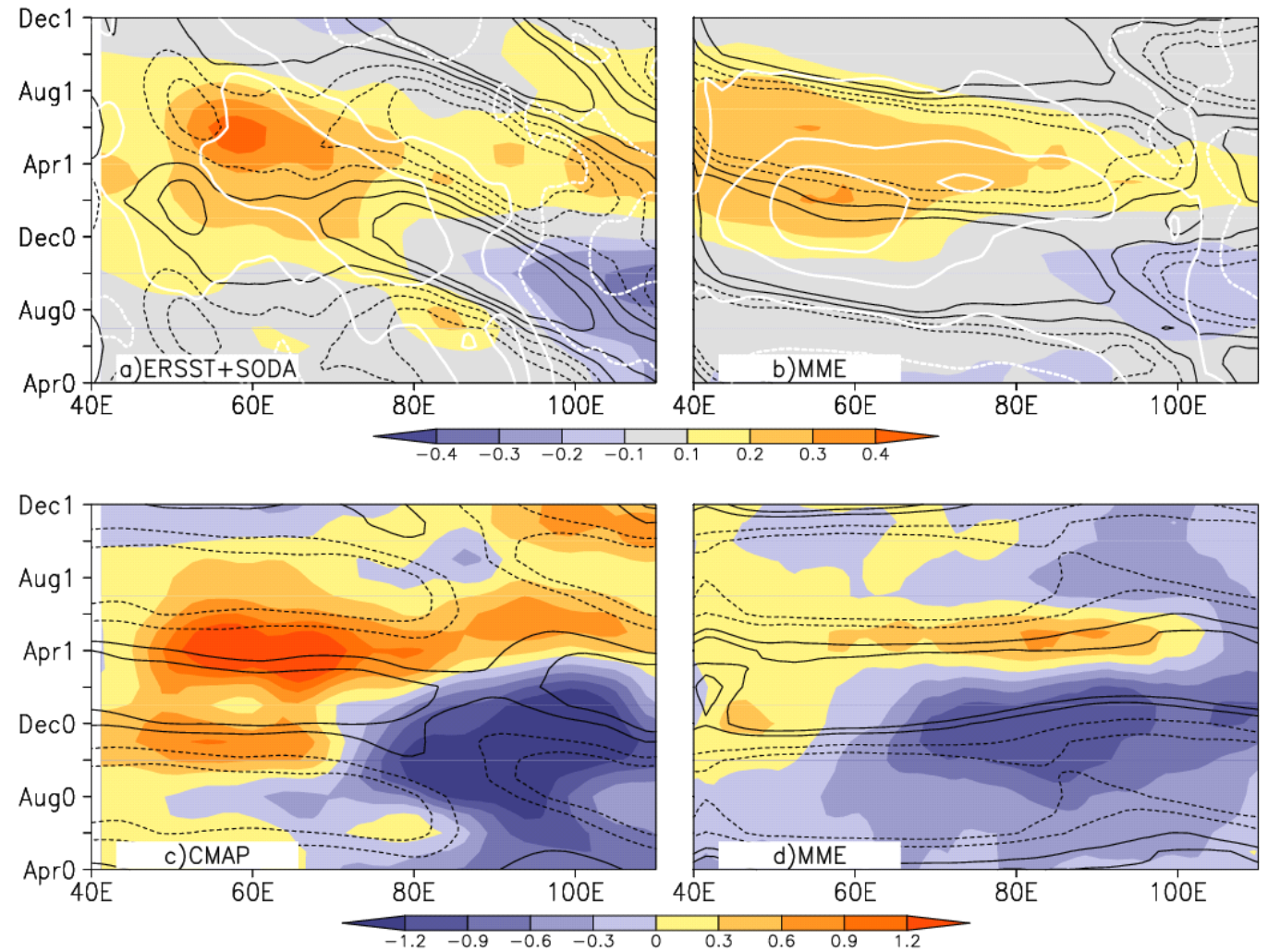

Fig. 9 Longitude-time sections averaged in $8^{\circ} \mathrm{S}-12^{\circ} \mathrm{S}$ : a, b) SST (color shading, ${ }^{\circ} \mathrm{C}$ ) and SSH (white contour line, $\mathrm{CI}=2 \mathrm{~cm})$, expressed as regression upon the $\mathrm{NDJ}(0 / 1)$ Niño3.4 index, and $\mathrm{SSH}$ seasonal climatology (black contour, $\mathrm{CI}=2 \mathrm{~cm}$ ), c, d) precipitation (color shading, $\mathrm{mm} / \mathrm{d}$ ), expressed as regression upon the $\mathrm{NDJ}(0 / 1)$ Niño3.4 index, and precipitation seasonal climatology (black contour, $\mathrm{CI}=0.9 \mathrm{~mm} / \mathrm{d})$.

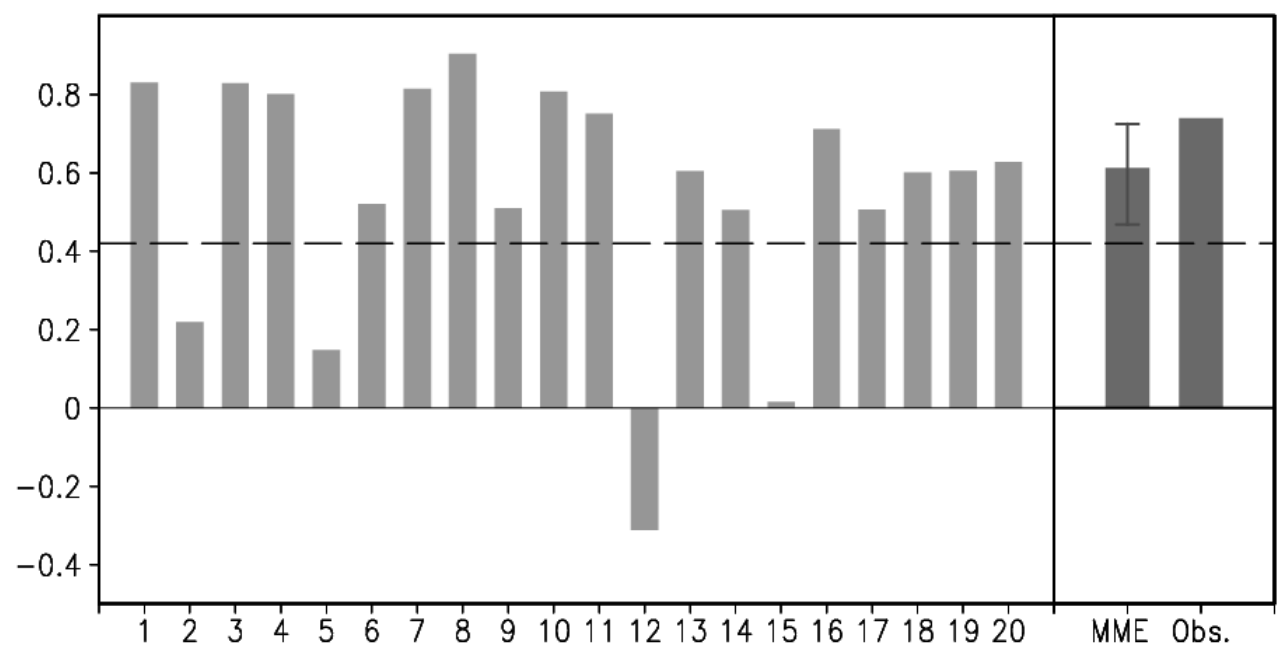

Fig. 10 The correlation between SSHa and SSTa averaged in SWIO $\left(15^{\circ} \mathrm{S}-5^{\circ} \mathrm{S}, 55^{\circ} \mathrm{E}-75^{\circ} \mathrm{E}\right)$ during MAM season for 20 models. Dark gray bars in the right present 20 models ensemble mean and observations. Numbers indicate the models listed in Table 1. Dashed line denotes statistical significance at the $95 \%$ confidence level on a $t$ test. The interval of $95 \%$ confidence level across the models is marked in MME, which is calculated on the Fisher transformation of the correlation (Fisher, 1921). 

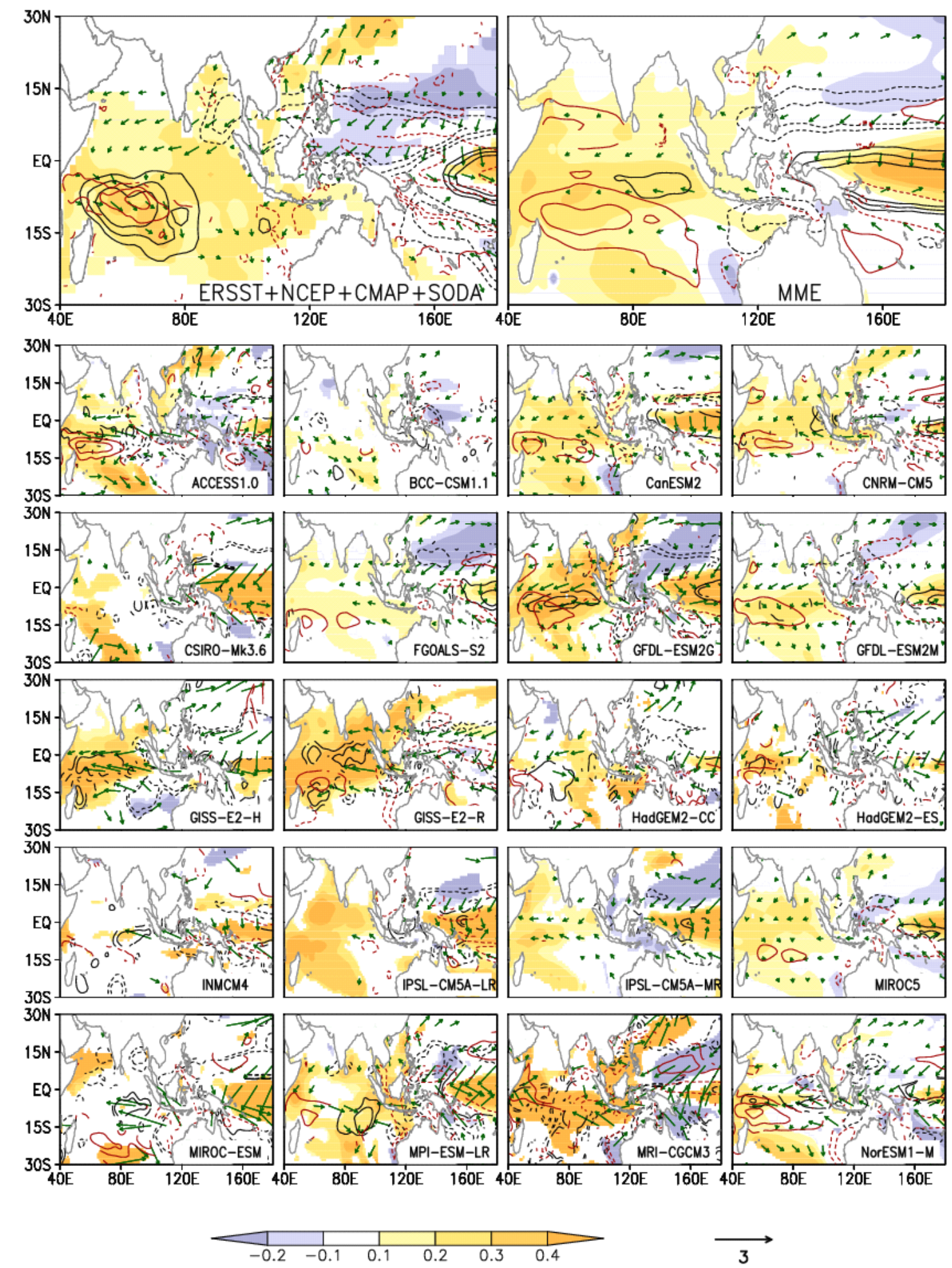

Fig. 11 Regression upon the NDJ(0/1) Niño-3.4 index for MAM(1): SST (color shading, ${ }^{\circ} \mathrm{C}$ ), surface wind (vector, $\mathrm{m} / \mathrm{s}$ ), sea level height (red contour, $\mathrm{CI}=2 \mathrm{~cm}$ ), and precipitation (black contour, $\mathrm{CI}=0.6 \mathrm{~mm} /$ day) over $90 \%$ confidence level on a $t$ test. 


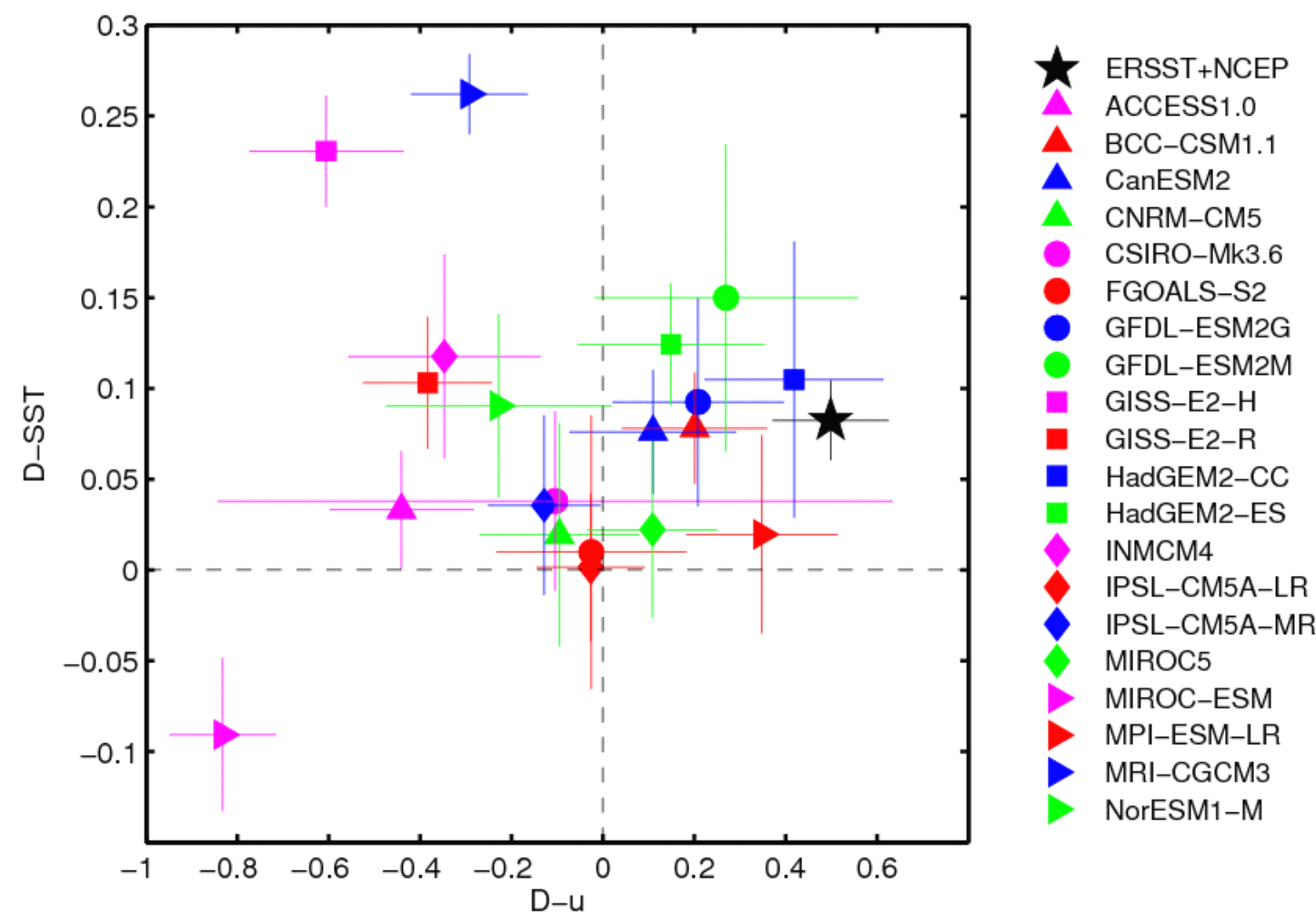

Fig. 12 Scatter diagram of the relationship between zonal wind anomaly and SSTa of SIO $\left(0^{\circ}-15^{\circ} \mathrm{S}\right.$, $\left.50^{\circ} \mathrm{E}-100^{\circ} \mathrm{E}\right)$ minus $\mathrm{NIO}\left(0^{\circ}-15^{\circ} \mathrm{N}, 50^{\circ} \mathrm{E}-100^{\circ} \mathrm{E}\right)$ in $\mathrm{MAM}(1)$. Error bars give ranges of one standard deviation. 


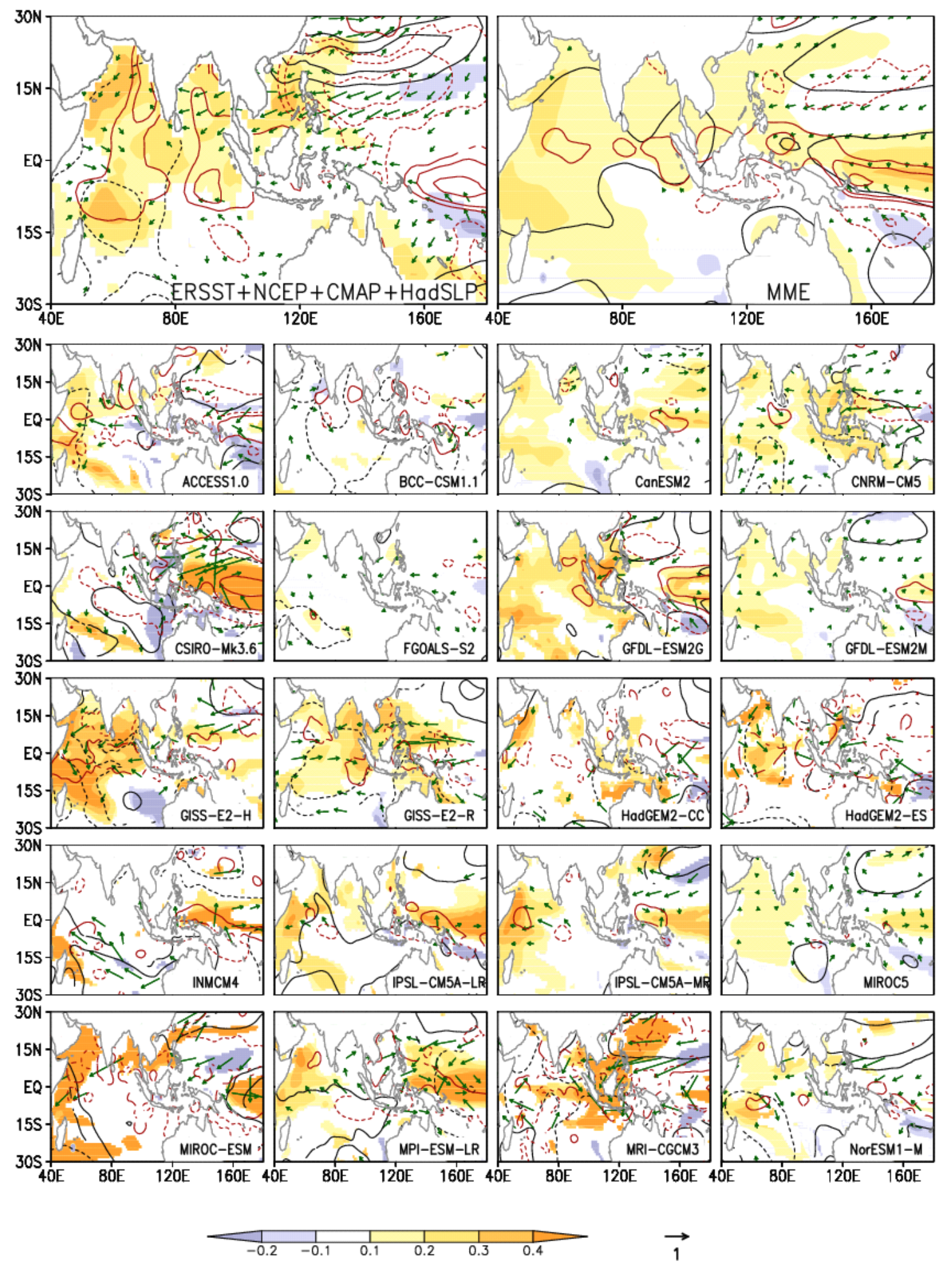

Fig. 13 Regression upon the $\mathrm{NDJ}(0 / 1)$ Niño-3.4 index for JJA(1): SST (color shading, ${ }^{\circ} \mathrm{C}$ ), surface wind (vector, $\mathrm{m} / \mathrm{s}$ ), precipitation (red contour, $\mathrm{CI}=0.3 \mathrm{~mm} /$ day), and SLP (black contour, $\mathrm{CI}=0.1 \mathrm{hPa}$ ) over $90 \%$ confidence level on a $t$ test. 

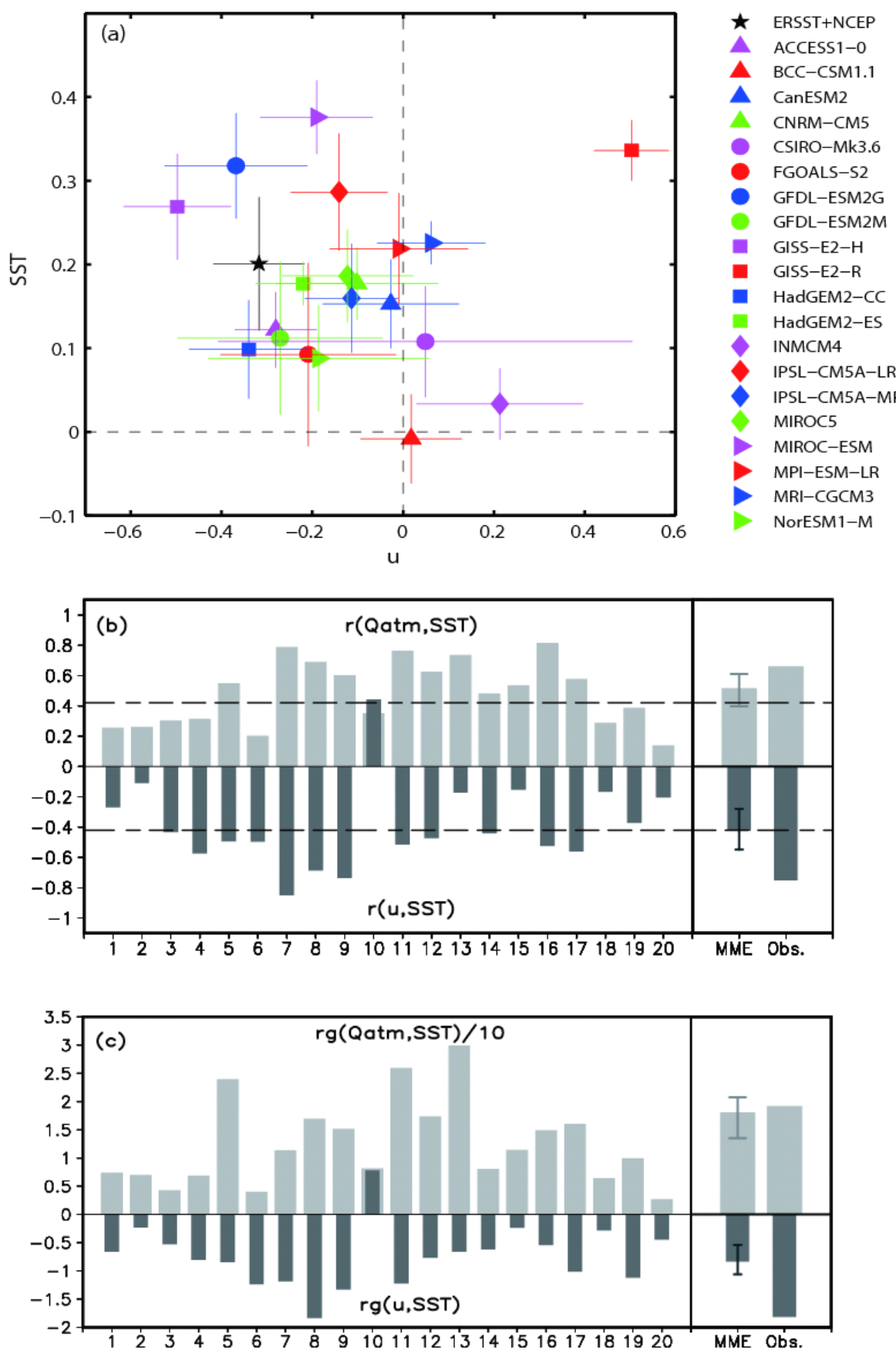

Fig. 14 a) Scatter diagram of the relationship between Qatm/zonal wind anomaly $\left(\mathrm{W} / \mathrm{m}^{2}\right.$ and $\mathrm{m} / \mathrm{s}$, respectively) and $\mathrm{SSTa}\left({ }^{\circ} \mathrm{C}\right)$ in $\mathrm{NIO}\left(0^{\circ}-15^{\circ} \mathrm{N}, 50^{\circ} \mathrm{E}-100^{\circ} \mathrm{E}\right)$ in $\operatorname{AMJ}(1)$. b) Correlation between Qatm/zonal wind anomaly and SSTa in NIO $\left(0^{\circ}-15^{\circ} \mathrm{N}, 50^{\circ} \mathrm{E}-100^{\circ} \mathrm{E}\right)$ in $\mathrm{AMJ}(1)$ for 20 models, respectively. c) same as b), except for regression, and Qatm regression on SSTa is divided 10 for a better vision. Note Qatm is defined as the atmospheric forcing component in the latent heat flux, due to atmospheric adjustments in wind speed, relative humidity, and surface air-sea temperature difference, defined as the latent heat flux minus the Newtonian cooling term ( $\mathrm{Du}$ et al. 2009). Numbers indicate the models listed in Table 1. Dashed line denotes statistical significance at the 95\% confidence level for $\mathrm{r}(\mathrm{Qatm}, \mathrm{SST})$ and $\mathrm{r}(\mathrm{u}, \mathrm{SST})$ on a $t$ test. In b) and $\mathrm{c})$, the interval of $95 \%$ confidence level across the models is marked in MME, which is calculated on the Fisher transformation of the correlation (Fisher, 1921). 

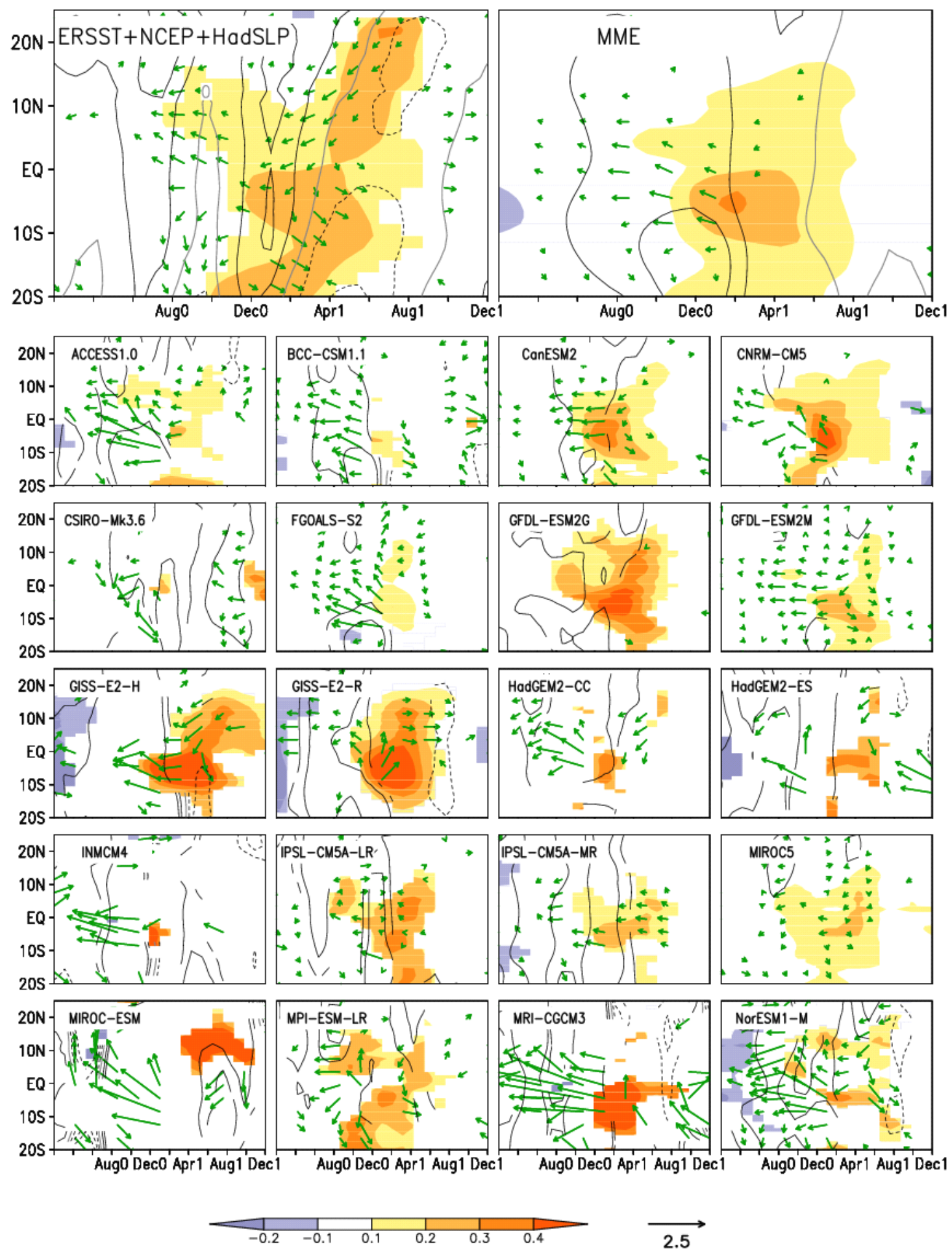

Fig. 15 Regressions upon NDJ(0/1) Niño3.4 index as a function of calendar month and latitude for SST (color shading, ${ }^{\circ} \mathrm{C}$ ) averaged over TIO $\left(40^{\circ} \mathrm{E}-100^{\circ} \mathrm{E}\right)$, surface wind (vectors, $\mathrm{m} / \mathrm{s}$ ) averaged over $40^{\circ} \mathrm{E}-80^{\circ} \mathrm{E}$ and SLP averaged over $40^{\circ} \mathrm{E}-80^{\circ} \mathrm{E}$ (contour, $\mathrm{CI}=0.2 \mathrm{hPa}$ ) over $90 \%$ confidence level on a $t$ test. 


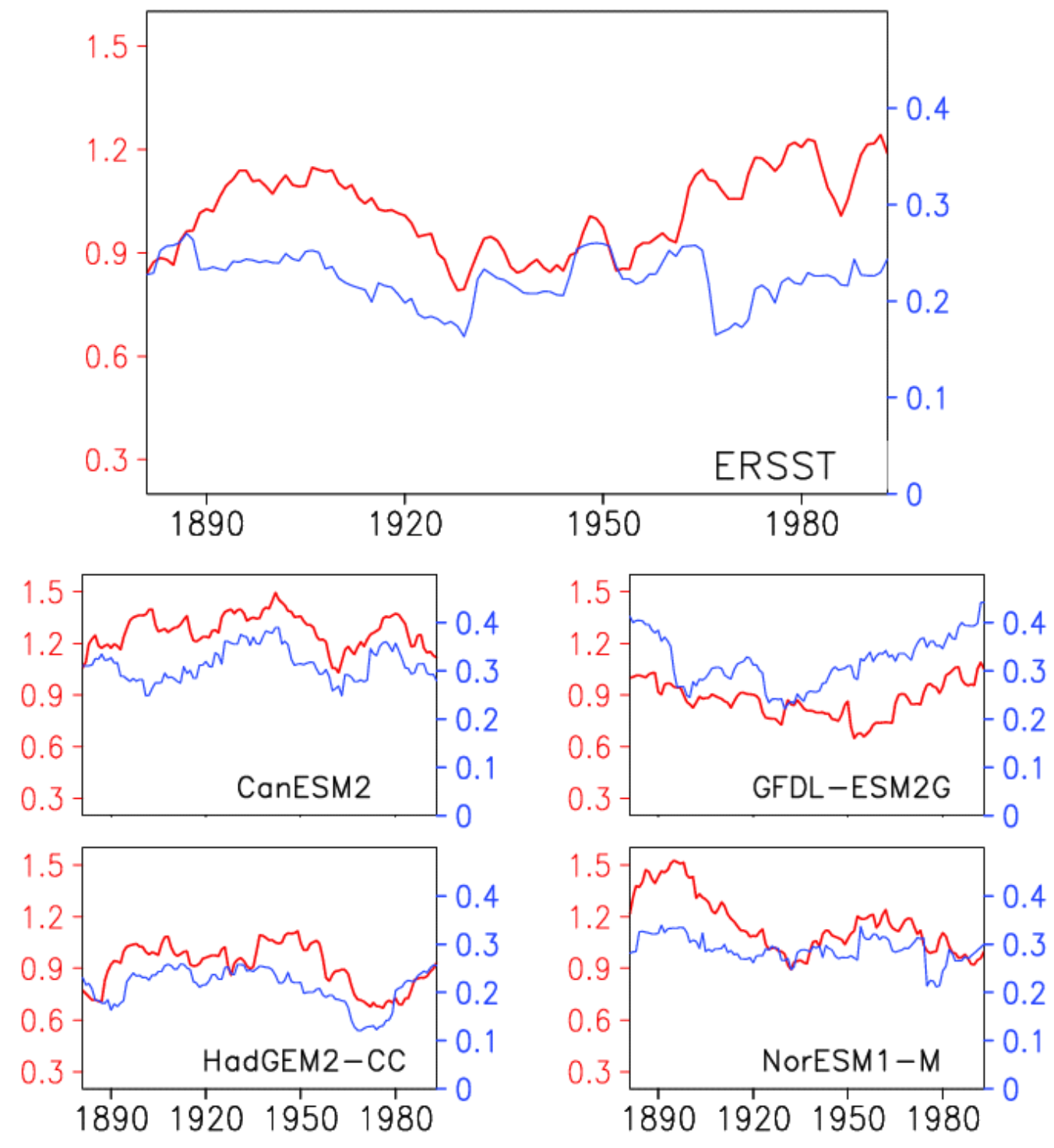

Fig. 16 21-yr running standard deviation (STD) of Niño3.4 NDJ (red line) and TIO MJJ SST indices (blue line). 

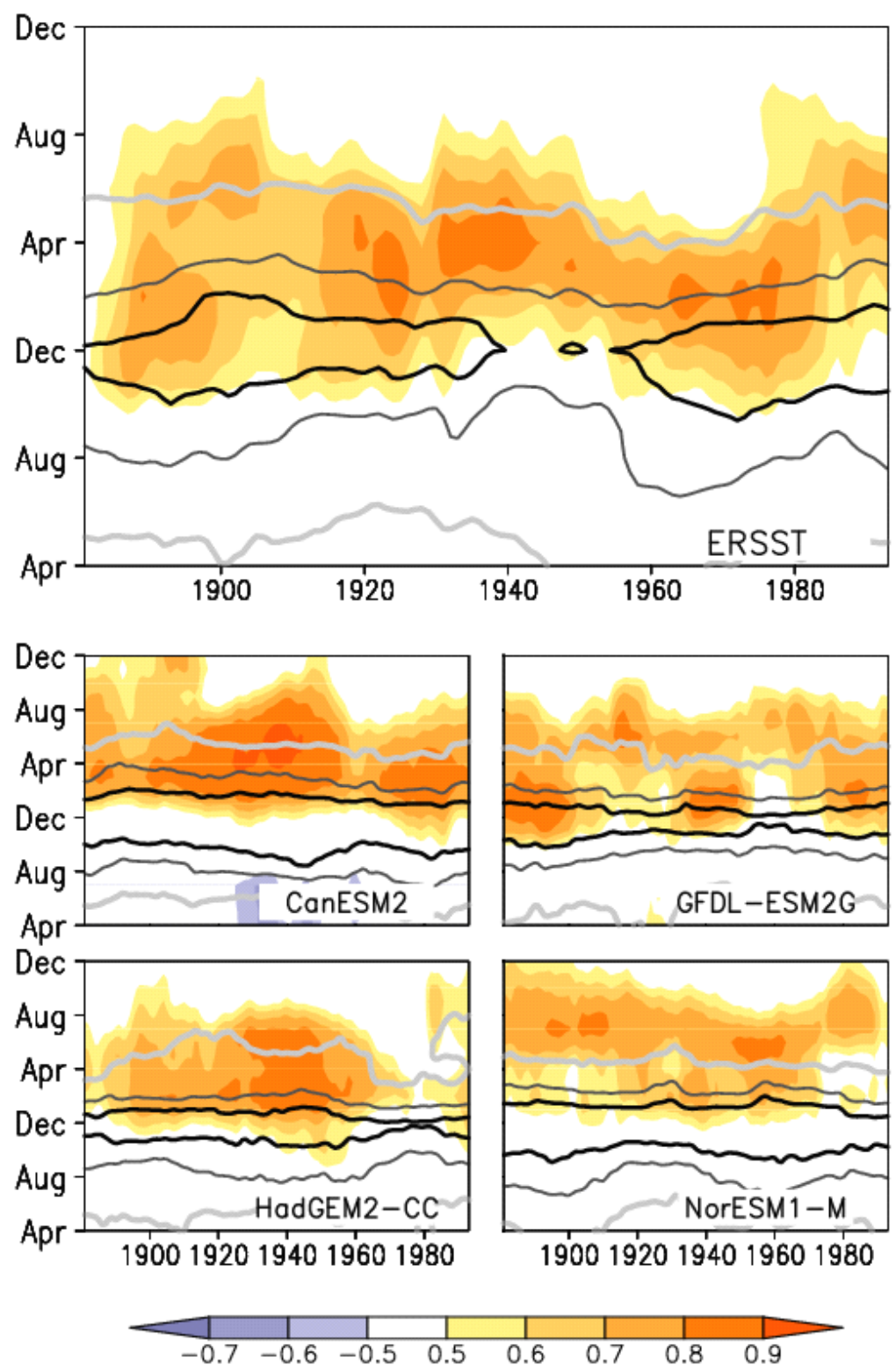

Fig. 17 21-yr running correlation with the NDJ(0/1) Niño3.4 index: TIO (color shading) and Niño3.4 SST (contours, light grey, dark grey and black line show 0.5, 0.9 and 0.975, respectively). 

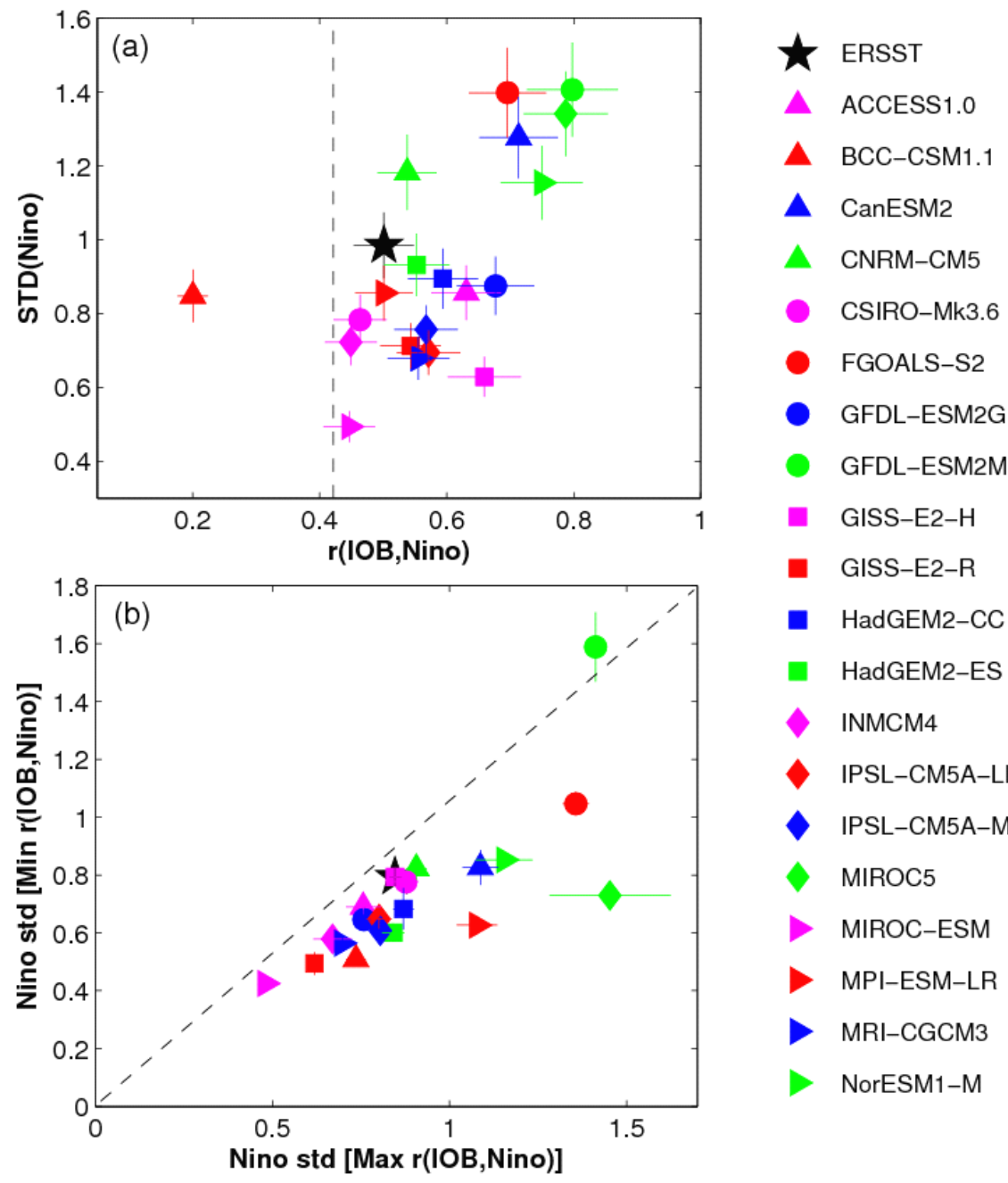

- HadGEM2-CC

- HadGEM2-ES

- INMCM4

- IPSL-CM5A-LR

- IPSL-CM5A-MR

- MIROC5

$>$ MIROC-ESM

- MPI-ESM-LR

> MRI-CGCM3

$>$ NorESM1-M

Fig. 18 Scatter diagram: a) correlation between NDJ(0/1) Niño3.4 with JJA(1) IOB indices [r(IOB, Niño)] against standard deviation of NDJ(0/1) Niño3.4 index [STD(Niño)]; b) STD(Niño) during decades when $\mathrm{r}(\mathrm{IOB}$, Niño) reaches the maximum against that during decades when $\mathrm{r}$ (IOB,Niño) reaches the minimum (analysis covers 1870-2005). The standard deviation and correlation are calculated in 21-yr running windows. Error bars give ranges of one standard deviation. 

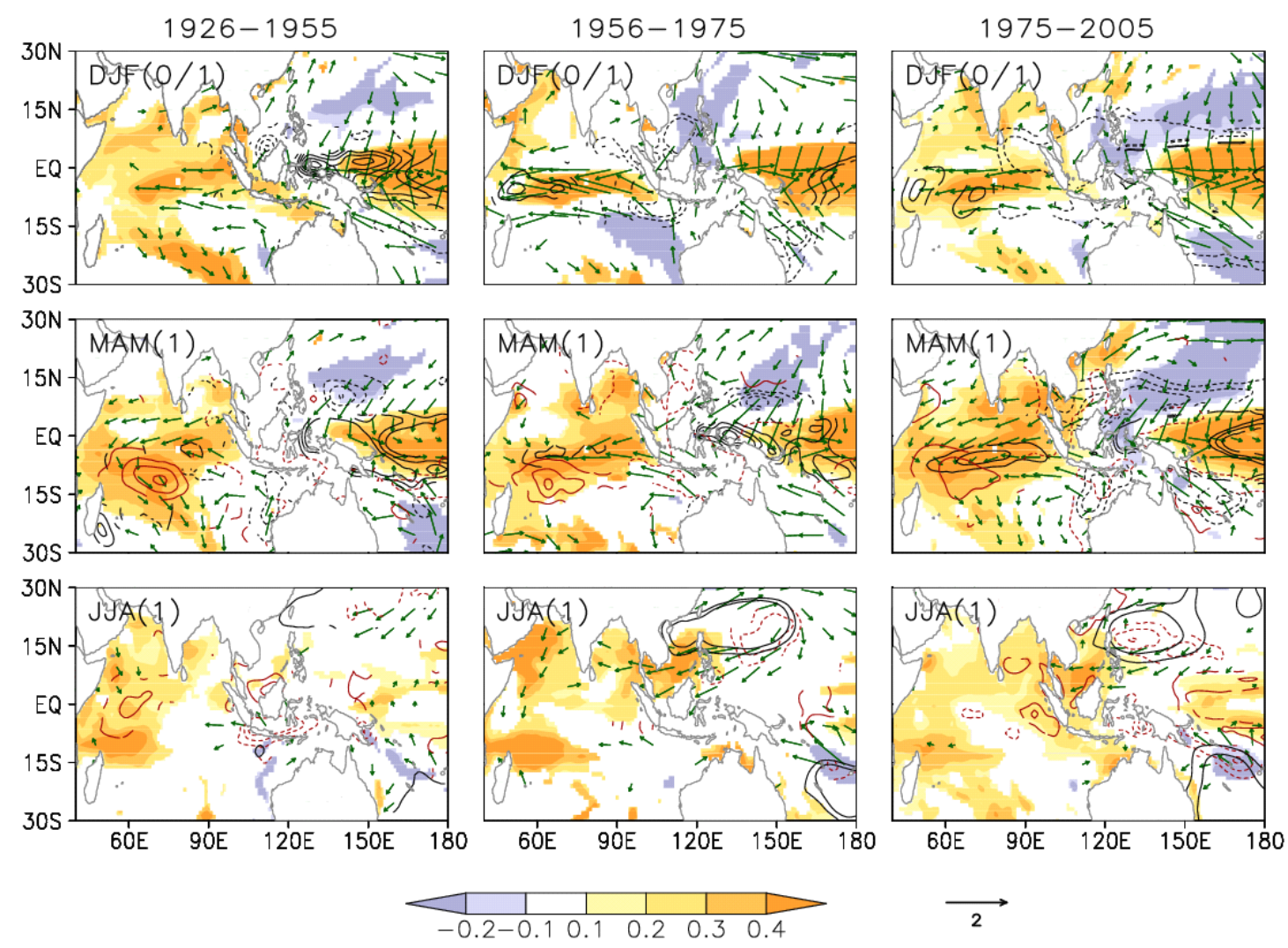

Fig. 19 Regression upon the NDJ(0/1) Niño-3.4 index for DJF(0/1), MAM(1) and JJA(1): SST (color shading, ${ }^{\circ} \mathrm{C}$ ), surface wind (vector, $\mathrm{m} / \mathrm{s}$ ), precipitation [black contour in $\operatorname{DJF}(0)$ and MAM(1), red contour in $\mathrm{JJA}(1), \mathrm{CI}=0.3 \mathrm{~mm} / \mathrm{d}$ ], sea level height [red contour in $\mathrm{MAM}(1), \mathrm{CI}=2 \mathrm{~cm}$ ], and SLP [black contour in JJA(1), CI $=0.1 \mathrm{hPa}$ ] over $90 \%$ confidence level on a $t$ test in periods $1926-1955$, 1956-1975, and 1976-2005 for GFDL-ESM2G. 